\title{
Analysis of Rubberized Self-Compacting Concrete under Uniaxial Tension by 3D Mesoscale Models
}

\author{
Hongguo Diao, ${ }^{1}$ Xinquan Wang $\mathbb{D}^{1},{ }^{1}$ Yunliang Cui, ${ }^{1}$ Shangyu Han, ${ }^{2}$ and Changguang $\mathbf{Q i}^{3}$ \\ ${ }^{1}$ Zhejiang University City College, Hangzhou 310015, China \\ ${ }^{2}$ College of Civil and Architectural Engineering, Nanchang Hangkong University, Nanchang 330063, China \\ ${ }^{3}$ College of Architecture, Civil Engineering and Environment, Ningbo University, Ningbo 315211, China
}

Correspondence should be addressed to Xinquan Wang; wangxq@zucc.edu.cn

Received 21 July 2020; Revised 9 October 2020; Accepted 12 November 2020; Published 7 December 2020

Academic Editor: Wenbing Wu

Copyright (c) 2020 Hongguo Diao et al. This is an open access article distributed under the Creative Commons Attribution License, which permits unrestricted use, distribution, and reproduction in any medium, provided the original work is properly cited.

Damage and failure of rubberized self-compacting concrete (RSCC) are studied by mesostructural models. The models include six phases: mortar, aggregates, rubber particles, aggregate-mortar interfacial transaction zones (A-M ITZs), rubber-mortar interfacial transaction zones (R-M ITZs), and voids. Thin layers between mortars and aggregates and between mortars and rubber particles represent A-M ITZs and R-M ITZs, , respectively. Aggregates and rubber particles are modeled with linear elastic, while mortars, A-M ITZs, and R-M ITZs are with different damage-plasticity behaviors. The mesoscale models are validated by the comparison of numerical results and experimental results. The effects of essential phase parameters on the composite's strength are evaluated, and empirical laws for these effects are established by data regression. It is demonstrated that the effect of porosity, size, and content of rubber particles affect strength and toughness, which provides guidance to the design of such composites for practical applications.

\section{Introduction}

The growth of the world population and economic development leads to the accelerated generation of solid wastes and poses challenges for their recycling. A large proportion of solid waste comes from used tires. The most common way to deal with tire rubber is by burning, which can lead to severe hazards [1]. Another way is to dump the scrap tires in sanitary landfills, which causes significant environmental risk and contamination. One of the most effective and environmentally friendly ways is to use recycled tire rubber as a partial substitute for aggregates in concrete.

The possibility for full utilization of rubber incorporation into concrete has been a subject of several experimental studies. The mechanical properties of concrete change with the incorporation of rubber. Topcu [2] reported a 50\% decrease of the cube and cylinder compressive strength and a $64 \%$ decrease of the tensile strength of concrete mixed with fine rubber particles. Furthermore, the use of coarse rubber aggregates leads to a reduction of cylinder and cube compressive strengths by $60 \%$ and $80 \%$, respectively, and $74 \%$ for tensile strength. These results indicate that the coarse rubber aggregate has a more substantial negative effect than the fine rubber aggregate. Similar findings were reported by Eldin and Senouci [3] and Su et al. [4]. However, the results obtained by Fattuhi and Clark [5] indicated the opposite trend. They found that adding graded coarse rubber granules leads to less strength decrease than the compressive strength of concrete less than the fine rubber particles. Fattuhi and Clark's findings were in agreement with Ali et al. [6]. Toutanji [7] investigated the effect of the replacement of coarse mineral aggregate by rubber tire aggregate. They found a reduction in both compressive and flexural strengths, showing a nonlinear relationship between the decrease in strength and volume of rubber aggregate in concrete. The differences in conclusions from previous research can be attributed to differences in the nature of the raw materials, test specimens, and test methods. But one common conclusion can be drawn from all experimental studies of rubber incorporation in concrete $[4,8]$. With the 
addition of rubber particles, the compressive and tensile strength of rubberized concrete decreased, but significant enhancements in the impact resistance and fracture toughness of concrete were observed.

Huang et al. [9] used a unit thickness cylindrical plane model and via finite element analysis and a parametric study, evaluated the effect of various design parameters on the composite strength. Feng et al. [10] studied the performance of the rubberized concrete specimen subjected to uniaxial compression by two- and three-dimensional mesoscale models, but the interfacial transaction zones between aggregate and mortar and between rubber particles and mortars were ignored. Xie et al. [11] presented an analysis of the entire process from fracture propagation to failure of the test piece through a mesoscale finite element model, where rubber concrete was considered as a four-phase composite containing rubber, coarse aggregate, mortar, and aggregatemortar interfacial transition zones (A-M ITZs). Existing numerical studies of rubberized concrete, like the ones mentioned above, do not contain all the phases in the real concrete. Specifically, they all ignore the voids and the rubber-mortar interfacial transition zones (R-M ITZs). To remedy this, Li et al. [12] proposed a mesoscale model containing all relevant phases in the concrete specimen and studied the mechanical properties, crack generation, and propagation of rubberized concrete. However, a systematic parametric study of the effects of key parameters is not provided.

From the above literature survey, it appears that the previous research was limited to experimental studies and qualitative explanations. Little work has been performed on theoretical modelling of rubberized concrete, with various limitations on the model's realism and quantitative results. Improved understanding of the damage and failure mechanisms in the presence of tire rubbers requires a more comprehensive and in-depth theoretical modelling and analysis, accurately to reveal the toughening effects.

This paper focused on establishing the effects of rubberized concrete microstructure on the observed macroscopic behavior. Here, rubberized concrete is treated as a multiphase composite material. A mesoscale model with six phases, aggregate, mortar, rubber particle, A-M ITZs, R-M ITZs, and voids, is used. The established comprehensive 3D mesoscale model and numerical simulation results were validated through comparing the results between simulation and experimental MTS results. A systematic parametric study is first conducted to evaluate the effect of various design parameters on the composite strength. The simulation results are analysed, leading to valuable statistical relations that will inform improved designs of rubberized concrete material and structures.

\section{Mesoscale Model and the Numerical Simulation Method}

2.1. Generation of the Mesoscale Model. The detailed procedure of generating a mesoscale-rubberized concrete sample has been given in [12]. Herein, only an outline is presented to facilitate the discussion of results.
The size distribution of aggregates and rubber particles was kept consistent with the prepared test specimens shown in Tables 1 and 2. Here, only coarse aggregates and rubber particles were explicitly modeled as mesoscale features. The sand, together with the cement matrix, was regarded as mortar. The coarse aggregates and rubber particles were considered to have spherical shapes. The A-M ITZs and R-M ITZs were thin layers attached to aggregates and rubber particles, respectively. Spherical voids were introduced in the mortar with a diameter between $2 \mathrm{~mm}$ and $4 \mathrm{~mm}$.

3D mesoscale numerical samples were generated with the following parameters: the sample dimensions were $50 \mathrm{~mm} \times 50 \mathrm{~mm} \times 150 \mathrm{~mm}$, the aggregates volume fraction of $30 \%$ was kept consistent with the tested specimen, the rubber particles volume fraction was $0,5 \%, 10 \%$, and $15 \%$, the porosity was $1 \%$, and the thickness of A-M ITZs and R-M ITZs was $0.6 \mathrm{~mm}$. Notably, this is larger than the actual ITZ thickness, but previous studies [13] have shown that the thickness of $0.6 \mathrm{~mm}$ can meet the required accuracy of numerical simulations. The size of the simulation models is half that of the test specimen to reduce the number of the element of models and improve computation efficiency. In order to prevent size differences from affecting the simulation results, all models in this paper have the same size.

2.2. Constitutive Behavior of Constituents. Several mesoscale models, considering the mesostructure and the local failure mechanisms in concrete, have been proposed in the last few decades, aiming at a better understanding of structural on the longer-scale response of concrete [14-16]. Continuumbased finite element models are the main approaches employed in the literature [17-22].

Each phase of the mesoscale model of concrete has distinct mechanical properties. For example, the stiffness and strength of coarse aggregates are higher than those of mortar and interfacial transaction zones. Therefore, aggregates are generally regarded as linear elastic materials in mesoscale models. The rubber, in principle, is a hyperelastic material when large deformations are allowed by the constraints. However, as part of the concrete, rubber particles will be constrained to small deformations, so the rubber material is also considered as a linear elastic material in this work. The incorporation of rubber makes the interface between rubber and mortar form a transaction zone similar to that between aggregate and mortar. However, the strength of the R-M ITZ zone is lower than that of A-M ITZ and much lower than that of mortar [16, 23-25].

The damage-plasticity model provides a general framework for modelling concrete and other quasibrittle materials by combining damage with separate tensile and the compressive plastic behavior. For mortar, A-M ITZs [18, 26], and R-M ITZs [12, 23], a concrete damaged-plasticity (CDP) model in ABAQUS [19] is employed in the present study. The deformation and failure behavior defined by the CDP model is composed of tensile cracking and compression crushing, as shown in Figure 1. Damage is controlled by two hardening parameters $\widetilde{\mathcal{\varepsilon}}_{t}^{p l}$ and $\widetilde{\varepsilon}_{c}^{p l}$ under tension and compression. 
TABLE 1: Coarse aggregate size distribution.

\begin{tabular}{lc}
\hline Sieve size $(\mathrm{mm})$ & Total passed percentage $(\%)$ \\
\hline 10 & 100 \\
8 & 60 \\
6 & 0 \\
\hline
\end{tabular}

TABLE 2: Rubber particle size distribution.

\begin{tabular}{lc}
\hline Sieve size $(\mathrm{mm})$ & Total passed percentage $(\%)$ \\
\hline 5 & 100 \\
3 & 60 \\
2 & 0 \\
\hline
\end{tabular}

In this paper, the general analytical expression for concrete hardening and softening proposed by Dacheng and Ruqi [20] was used. The mortar, A-M ITZs, and R-M ITZs are linear elastic materials before peak stress under tension. After the peak stress, the softening behavior is described by the following formula:

$$
\frac{\Sigma_{t}}{f_{t}}=\frac{\left(\varepsilon_{t} / \varepsilon_{t 0}\right)}{\alpha_{t}\left(\left(\varepsilon_{t} / \varepsilon_{t 0}\right)-1\right)^{1.7}+\left(\varepsilon_{t} / \varepsilon_{t 0}\right)},
$$

where $f_{t}$ and $\varepsilon_{t 0}$ are the peak stress and peak strain, respectively, and $\alpha_{t}$ is a coefficient which can be calculated by $\alpha_{t}=0.312 f_{t}^{2}$.

For uniaxial compression, the stress-strain response of the material remains linearly elastic until the yield stress $\sigma_{c 0}$, and the plastic response is characterized by stress hardening followed by strain-softening beyond the peak stress $\sigma_{c u}$. The stress-strain relationship is expressed as follows:

$$
\frac{\sigma_{c}}{f_{c}}=\left\{\begin{array}{l}
\frac{E_{0} \varepsilon_{c}}{f_{c}}, \quad \frac{\sigma_{c}}{f_{c}} \leq 0.4, \\
\alpha_{a} \frac{\varepsilon_{c}}{\varepsilon_{c u}}+\left(3-2 \alpha_{a}\right)\left(\frac{\varepsilon_{c}}{\varepsilon_{c u}}\right)^{2}+\left(\alpha_{a}-2\right)\left(\frac{\varepsilon_{c}}{\varepsilon_{c u}}\right)^{3}, \\
\frac{\sigma_{c}}{f_{c}}>0.4 \& \frac{\varepsilon_{c}}{\varepsilon_{c u}} \leq 1, \\
\frac{\left(\varepsilon_{c} / \varepsilon_{c u}\right)}{\alpha_{d}\left(\left(\varepsilon_{c} / \varepsilon_{c u}\right)-1\right)^{2}+\left(\varepsilon_{c} / \varepsilon_{c u}\right)}, \quad \frac{\varepsilon_{c}}{\varepsilon_{c u}}>1,
\end{array}\right.
$$

where $f_{c}$ and $\varepsilon_{c u}$ are the peak stress and peak strain, and $\alpha_{a}$ and $\alpha_{d}$ are two parameters calculated by $\alpha_{a}=2.4-0.0125 f_{c}$ and $\alpha_{d}=0.157 f_{c}^{0.785}-0.905$.

The uniaxial stress-strain curve can be converted into the stress-plastic strain curve through the following formulas:

$$
\begin{aligned}
& \widetilde{\varepsilon}_{t}^{p l}=\widetilde{\varepsilon}_{t}^{c k}+\varepsilon_{t 0}^{e l}-\varepsilon_{t}^{e l}, \\
& \widetilde{\varepsilon}_{c}^{p l}=\widetilde{\varepsilon}_{c}^{i n}+\varepsilon_{c 0}^{e l}-\varepsilon_{c}^{e l} .
\end{aligned}
$$

In equations (3) and (4), $\widetilde{\varepsilon}_{t}^{p l}$ and $\widetilde{\varepsilon}_{c}^{p l}$ are the equivalent plastic strains in uniaxial tension and uniaxial compression, respectively, $\widetilde{\varepsilon}_{t}^{c k}$ and $\widetilde{\varepsilon}_{c}^{i n}$ are the cracking strains for tension and inelastic strain for compression, and $\varepsilon_{t 0}^{e l}, \varepsilon_{c 0}^{e l}, \varepsilon_{t}^{e l}$, and $\varepsilon_{c}^{e l}$ can be calculated by the following equations:

$$
\begin{aligned}
& \varepsilon_{t 0}^{e l}=\frac{\sigma_{t}}{E_{0}}, \\
& \varepsilon_{c 0}^{e l}=\frac{\sigma_{c}}{E_{0}}, \\
& \varepsilon_{t}^{e l}=\frac{\sigma_{t}}{\left(1-d_{t}\right) E_{0}}, \\
& \varepsilon_{c}^{e l}=\frac{\sigma_{c}}{\left(1-d_{c}\right) E_{0}},
\end{aligned}
$$

where $d_{t}$ and $d_{c}$ are the tensile and compression damage factors, respectively, with values in the interval $(0,1)$. The value 0 represents the undamaged material, and the value 1 represents the complete failure of the material.

The stress-strain relationship of concrete under uniaxial tension and compression loading can be expressed by the following equations, respectively.

$$
\begin{aligned}
& \sigma_{t}=\left(1-d_{t}\right) E_{0}\left(\varepsilon_{t}-\widetilde{\varepsilon}_{t}^{p l}\right), \\
& \sigma_{c}=\left(1-d_{c}\right) E_{0}\left(\varepsilon_{c}-\widetilde{\varepsilon}_{c}^{p l}\right) .
\end{aligned}
$$

Uniaxial tension and compression strains can be expressed as follows:

$$
\begin{aligned}
& \varepsilon_{t}=\widetilde{\varepsilon}_{t}^{c k}+\varepsilon_{t 0}^{e l}, \\
& \varepsilon_{c}=\widetilde{\varepsilon}_{c}^{i n}+\varepsilon_{c 0}^{e l} .
\end{aligned}
$$

Two damage criteria were employed to describe the different effects under tension and compression:

$$
\begin{aligned}
& d_{t}=1-\frac{\left(\sigma_{t} / E_{0}\right)}{\widetilde{\varepsilon}_{t}^{p l}\left(1 / b_{t}-1\right)+\left(\sigma_{t} / E_{0}\right)}, \\
& d_{c}=1-\frac{\left(\sigma_{c} / E_{0}\right)}{\widetilde{\varepsilon}_{t}^{p l}\left(1 / b_{c}-1\right)+\left(\sigma_{c} / E_{0}\right)},
\end{aligned}
$$

where $b_{t}$ and $b_{c}$ are the two constant factors, which can be calculated by $b_{t}=\widetilde{\varepsilon}_{t}^{p l} / \widetilde{\varepsilon}_{t}^{c k}$ and $b_{c}=\widetilde{\varepsilon}_{c}^{p l} / \widetilde{\varepsilon}_{c}^{c k}$. Birtel and Mark [21] suggested that $b_{t}=0.1$ and $b_{c}=0.7$.

2.3. Definition of Macroscopic Properties and Statistical Analyses. The focus of this work is on the tensile strength and toughness of rubber concrete. Material strength refers to the mean value of the maximum stress on the stress-strain curve (maximum load divided by the cross-sectional area) of the numerical simulation results for several mesoscale models.

The influence of rubber particle volume content and porosity on the strength of rubber self-compacting concrete was evaluated by the statistical method. The standard deviation of $n$ simulation results can be obtained by the following equation:

$$
s^{2}=\frac{1}{n-1} \sum_{i=1}^{n}\left(x_{i}-\bar{x}\right)^{2},
$$

where $\bar{x}$ is the average value of $x_{i}$. 


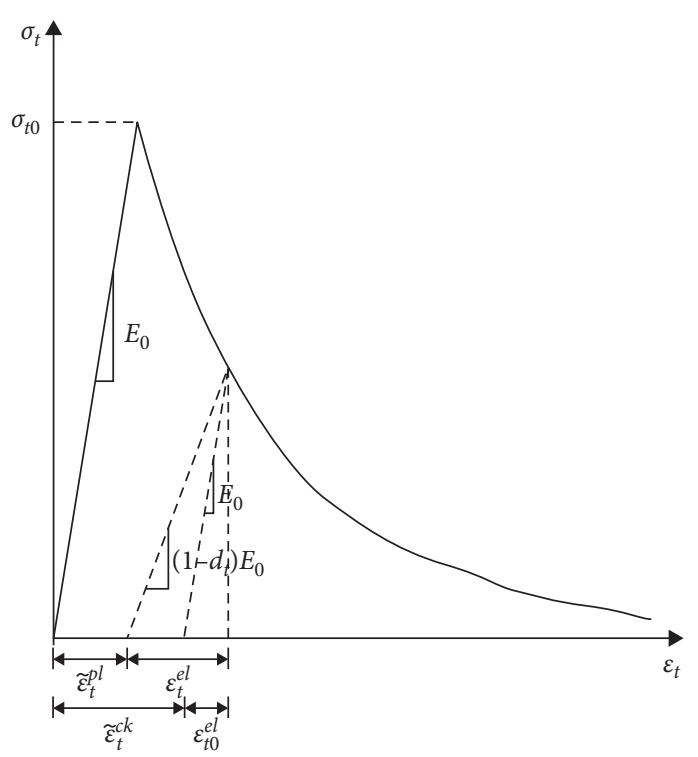

(a)

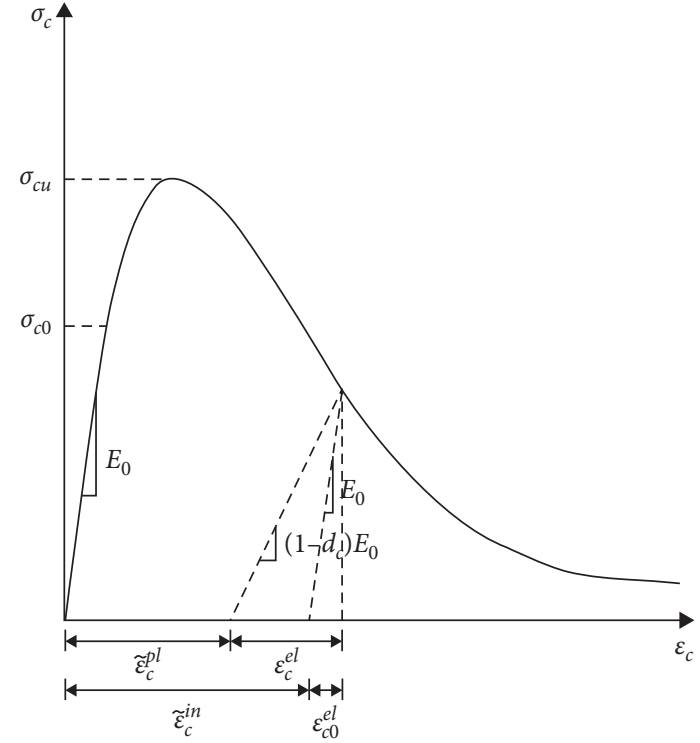

(b)

Figure 1: Schematic diagrams of concrete response under uniaxial tension and compression. (a) Tension. (b) Compression.

2.4. FE Analyses Setup. The compressive strength, tensile strength, and young's modulus are obtained from the tensile and compressive experiments of the same size mortar specimen. The parameters used for the simulations are shown in Table 3. The rubber particle and aggregate are all sphere particles to simplify the modelling process, aggregates are assumed to be linear elastic materials, and the parameters of these two materials are kept constant in all the samples. The mortar, A-M ITZs, and R-M ITZs are materials with damage-plasticity [22, 27-29]. The parameters of A-M ITZs and R-M ITZs are also kept constant in all samples, but mortar in samples with different rubber volume fractions is different because of the change of the sand volume. The mortar parameters in the table are mean values obtained through compressive and tensile tests of prepared mortar specimens. Based on the past research of rubberized concrete, the tensile strength and compressive strength of A-M ITZ and R-M ITZ are much lower than that of mortar, and R-M ITZ's are much lower than A-M ITZ's; the parameters of A-M ITZ and R-M ITZ are obtained through trial and error.

Displacements of one end of the prismatic samples were constrained in a direction normal to the plane, and the load was applied on the opposite end via prescribed displacements. These boundary conditions are shown in Figure 2. All simulations are performed using ABAQUS/ standard. Force and displacement variables are extracted to calculate stress and strain by the self-written python code. Since the crack is not modeled explicitly in this paper, the development of cracks is judged by the SDEG value. The range of SDEG value is $[0,1]$. When the SDEG value is less than 0.5 , it means there is no damage to the element. When the SDEG value is more significant than 0.5 , it means that the element has started cracking.

\section{Model Validation}

3.1. Mesh Sensitivity Analysis. Prior to validating the mesoscale models established in this paper, a mesh sensitivity study was conducted. When using finite element software to carry out mesoscopic numerical simulation of rubber concrete, the mesh size can affect the accuracy of the calculation, and it is also a key factor affecting the calculation time and speed. Three models of RSCC with 5\% rubber content with identical geometric features, namely, the aggregate size, aggregate distribution, rubber particle size, rubber particle distribution, voids size, and voids distribution, are meshed by three grid sizes of $0.4 \mathrm{~mm}, 0.5 \mathrm{~mm}$, and $0.6 \mathrm{~mm}$, respectively. The mesoscale model of three different grid sizes is shown in Figure 3. No apparent differences can be observed in Figure 3. However, the average number of elements are approximately 1.3 million with $0.4 \mathrm{~mm}$ mesh size, approximately 0.97 million with $0.5 \mathrm{~mm}$ mesh size, and approximately 0.76 million with $0.6 \mathrm{~mm}$ mesh size.

The uniaxial tensile simulations of these mesoscopic models were carried out using the parameters in Table 3 . The stress-strain curves from the numerical simulations are shown in Figure 4, and the cracks, which eventually caused the overall failure of the entire test piece, are shown in Figure 4. As can be seen from the stress-strain curves, with the increase of the mesh size, there is no significant difference between the numerical simulation results. The maximum error between the calculated strength of the numerical simulation result is $3 \%$, and the strain value corresponding to the maximum tensile stress is very close. The elastic modulus of the calculated results of the nine groups is the same; so, the numerical simulation result of the model with the $0.6 \mathrm{~mm}$ mesh size is adequate. As the mesh size becomes more extensive, the total number of different 
TABLE 3: Material parameters for the RSCC mesoscale model.

\begin{tabular}{|c|c|c|c|c|c|}
\hline & Tensile strength $(\mathrm{MPa})$ & Compressive strength (MPa) & Young's modulus (GPa) & Poisson's ratio & Density $\left(\mathrm{kg} / \mathrm{m}^{3}\right)$ \\
\hline Coarse aggregate & - & - & 40 & 0.2 & 2600 \\
\hline Rubber particle & - & - & 7 & 0.4 & 1050 \\
\hline A-M ITZ & 3 & 45 & 21 & 0.2 & 1800 \\
\hline R-M ITZ & 1.5 & 25 & 12.5 & 0.2 & 1500 \\
\hline Mortar_SCC & 4.5 & 60 & 28 & 0.2 & 2200 \\
\hline Mortar_RSCC-5\% & 4.0 & 50 & 26 & 0.2 & 2200 \\
\hline Mortar_RSCC-10\% & 3.6 & 40 & 24 & 0.2 & 2200 \\
\hline Mortar_RSCC-15\% & 3.2 & 36 & 22 & 0.2 & 2200 \\
\hline
\end{tabular}

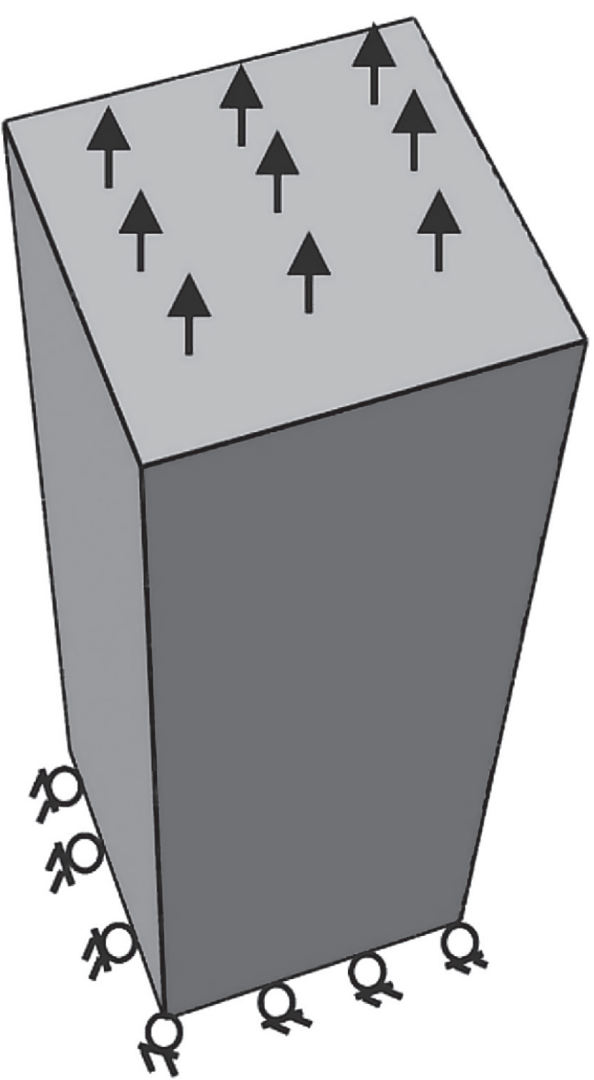

FIgURE 2: Specimen loading and boundary condition.

mesoscopic model elements decreases, and the computational time is shortened. It can be seen from Figure 5 that the crack position and the cracking pattern of model 1 are similar when the mesh size changes, and there is no significant difference in the crack. There is a big difference in the crack pattern between the different mesh sizes of model 2. As can be seen from Figure 5(b), when the mesh size becomes $0.5 \mathrm{~mm}$, the final fracture pattern of model 2 has changed from type I to type II $[30,31]$, there are two parallel cracks appeared in the specimen, and the postpeak decline speed of the corresponding stress-strain curve is slowed down which can be seen in Figure 4. As shown in Figure 5(b), with the increase of the mesh size, the fracture pattern changed again. Besides, the fracture position of model 3 changed apparently with the increase of mesh size, as shown in Figure 5(c). Therefore, the crack position and

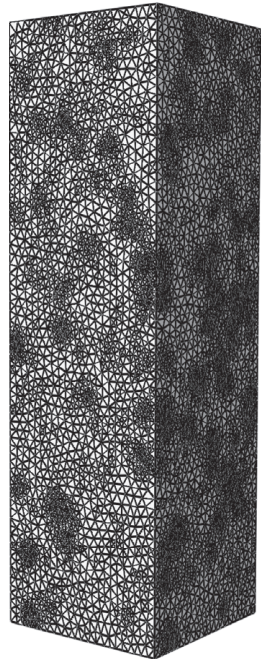

Mesh size $=0.4 \mathrm{~mm}$
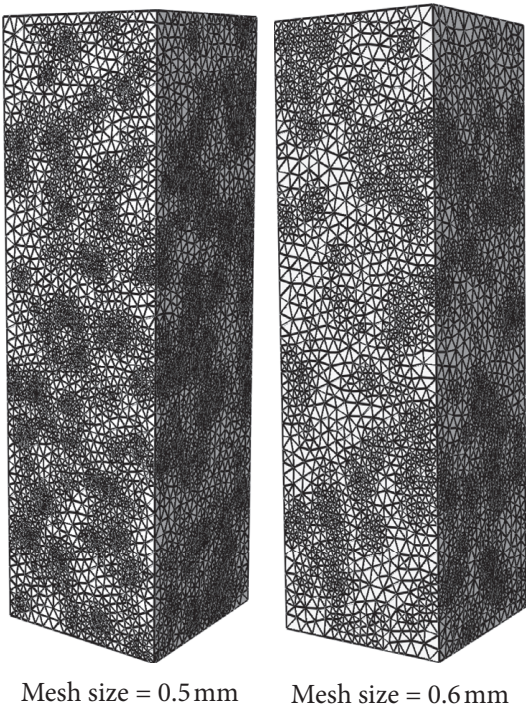

Figure 3: Mesoscale model of different mesh sizes.

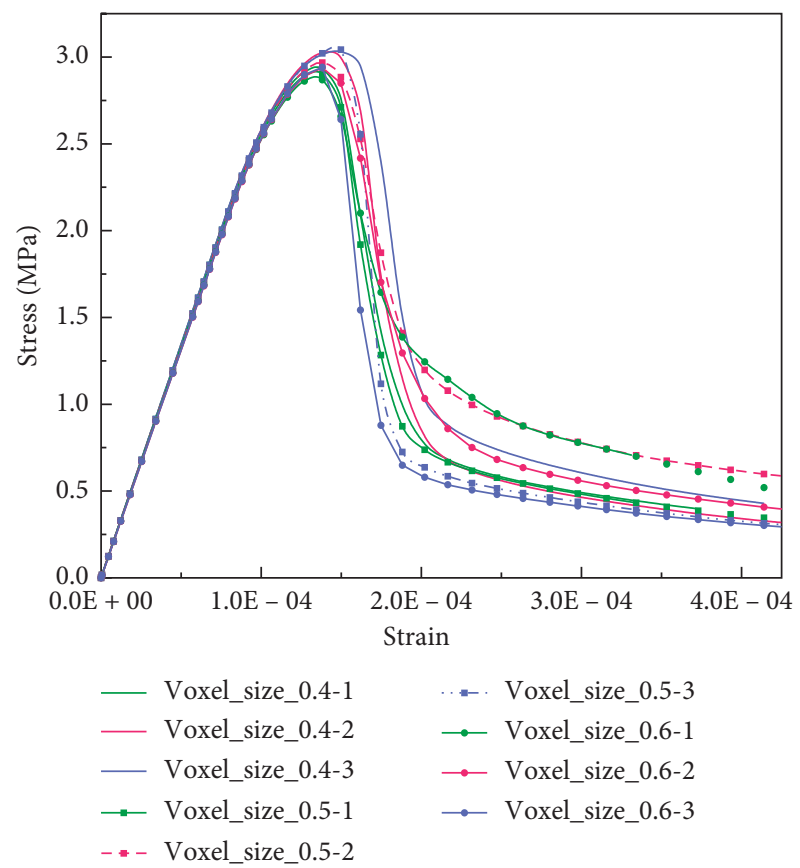

FIgURE 4: Stress-strain curves of different mesh size models. 


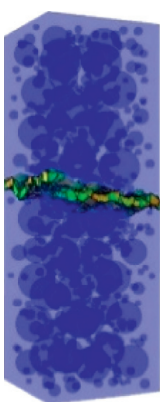

(A) voxel-0.4

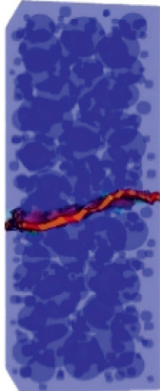

(B) voxel- 0.5 Model 1

(a)

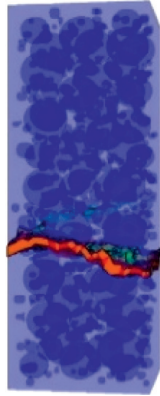

(C) voxel-0.6

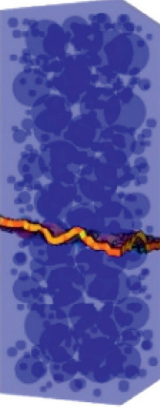

(A) voxel- 0.4

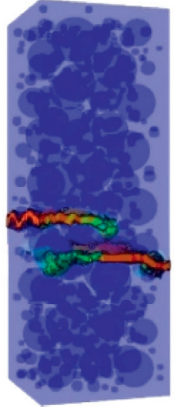

(B) voxel- 0.5 Model 2

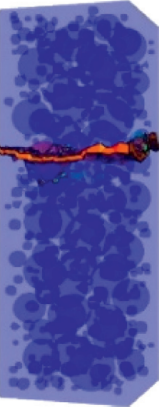

(C) voxel- 0.6

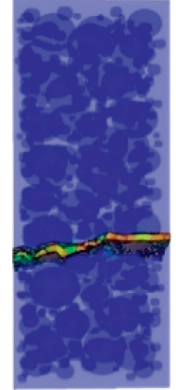

(A) voxel-0.4

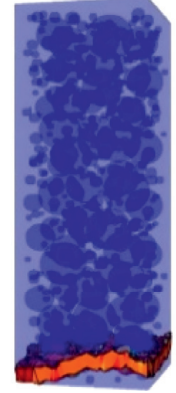

(B) voxel-0.5 Model 3

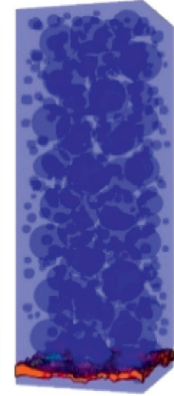

(C) voxel-0.6

(c)

FIgure 5: Crack patterns of varying mesh size models. (a) Model 1. (b) Model 2. (c) Model 3.

the crack mode may vary significantly with the change of the mesh size. The main reason is that the size of the grid increases, and some local components of the specimen change. For example, as the size of the grid increases, some pores and ITZs of some parts may be ignored as the grid cannot be meshed. However, the initial defects and weak ITZs of the test piece are the critical positions of the initial cracks. Therefore, the crack position of the test piece may change under different mesh sizes, but there is no significant difference between the stress and strain curves. The final fracture of this test piece [12] is shown in Figure 6. From Figure 6, comparing the failure crack patterns, it seems that the failure pattern is largely mesh dependent, and $0.4 \mathrm{~mm}$ mesh size results give better agreement with the experiment.

3.2. Results for Model Validation. The mesoscale modelling results are validated by comparing it with the test result conducted in [12]. The experimental and numerical stressstrain curves of RSCC under uniaxial tension are shown in Figure 7.

As shown in Figures 7(a), 7(c), and 7(d), the elastic modulus of the numerical simulation of SCC, RSCC-10\%, and RSCC-15\% are very close to the test result, and the strength is slightly smaller, with an error of $5.4 \%, 0.8 \%$, and $7.1 \%$ corresponding to SCC, RSCC- $10 \%$, and RSCC- $15 \%$. The postpeak curves are also slightly different, mainly because the postpeak behavior is controlled firmly by the development of cracks, which are random due to the material heterogeneity. In all previous numerical simulations of concrete, e.g., [22, 30, 32], the postpeak curve is close to the experimental results, but no full match can be achieved due to the same reasons. It is suggested that as long as the postpeak curve is close to experimentally measured, the numerical simulation result is sufficiently realistic.

Figure 7(b) shows the experimental and numerical simulation results for specimen RSCC-5\%. It can be seen from Figure 7(b) that there is a difference between strength predicted by the numerical simulation result and the experimental result. The error is 3.5\%. The elastic modulus of the simulated piece is slightly smaller than that of the actual specimen, but the simulation result is still reliable. It can also

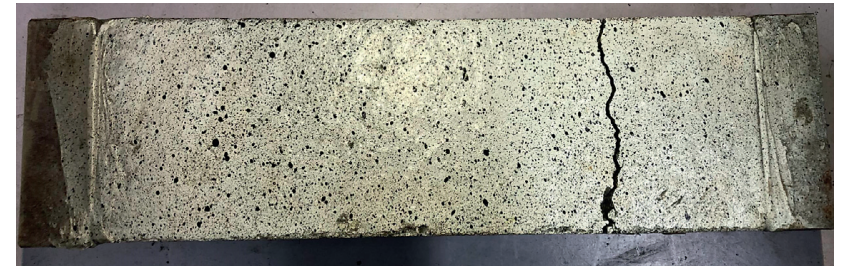

FIGURE 6: Crack patterns of RSCC-5\% test specimen.

be seen from the test stress-strain curve of specimen RSCC$5 \%$, and there is a turning point $A$. After the turning point, the softening curve begins to decline rapidly. Since the development of the postpeak crack of this test piece is more complicated, which can be seen in Figure 7(b), this turning point has not been captured by the simulations, resulting in more pronounced differences in the measured and predicted softening behavior. Nevertheless, the prepeak behavior and strength are in good agreement with experiments, similar to SCC, justifying the use of the model for parametric studies.

\section{Parametric Studies and Discussion}

\subsection{A-M ITZs and R-M ITZs Effects}

4.1.1. Presence of A-M ITZs and R-M ITZs. Four sets of 5\% rubberized concrete specimens with the same distribution of aggregate, rubber particles, and pores were used in this section to investigate the fracture properties of rubberized self-compacting concrete specimens under the uniaxial tensile load in the presence or absence of interfacial transaction zones. In model $a$, there are no A-M ITZs and R-M ITZs; model $b$ has fixed thickness A-M ITZs and no R-M ITZs; model $c$ has fixed thickness R-M ITZs and no A-M ITZs; model $d$ has fixed thickness of A-M ITZs and R-M ITZs. The fixed thickness is $0.6 \mathrm{~mm}$, where applicable. Three realizations were constructed for each model type, and the numerical simulation results for the realizations of the given model showed only small differences. Therefore, the average value of the uniaxial tension stress-strain curves was obtained and is shown in Figure 8. One typical crack pattern of the varying A-M ITZs and R-M ITZs thickness is shown 

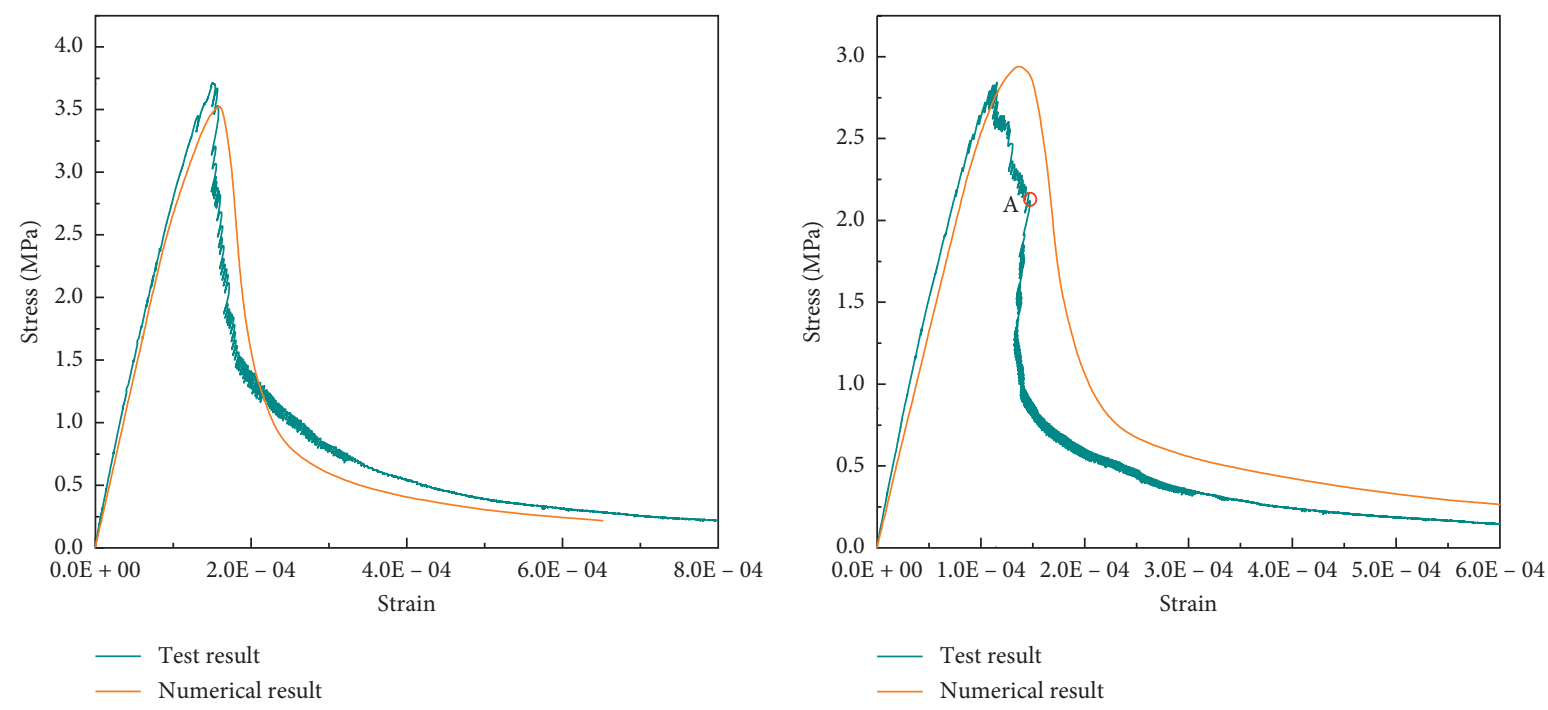

(a)

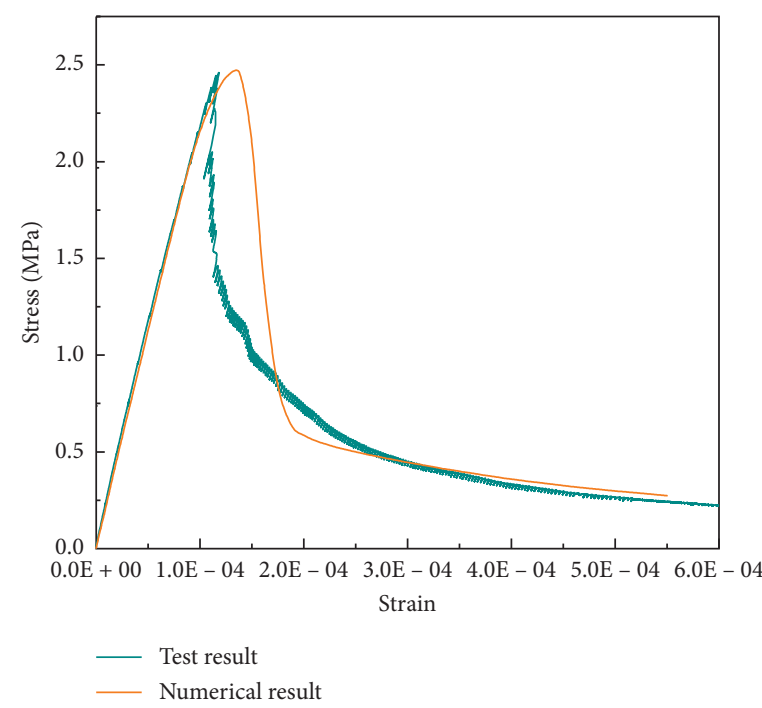

(c)

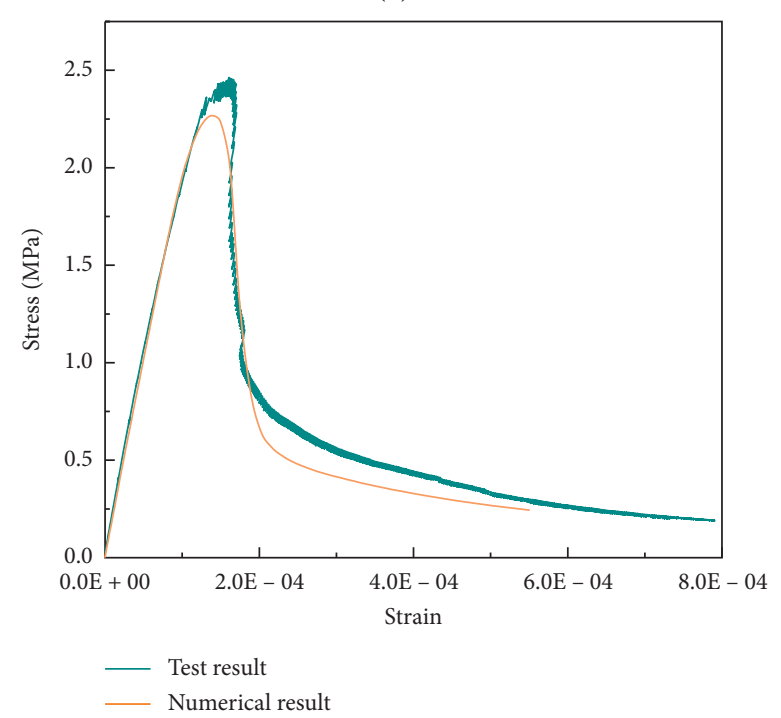

(d)

FIgURE 7: Stress-strain curve of specimen RSCC under uniaxial tension. (a) SCC. (b) RSCC-5\%. (c) RSCC-10\%. (d) RSCC-15\%.

in Figure 9, and the corresponding dissipated energy-strain curve is shown in Figure 10.

As can be seen from Figure 8, the presence or absence of the ITZs has little influence on prepeak stress-strain curves. This is because the ITZs occupy a small volume of the whole specimen and have little effect on the elastic behavior prior to damage initiation. However, the existence of ITZs has a pronounced influence on the maximum tensile stress of the specimen. The maximum tensile stress of the specimen without ITZs and its corresponding strain value are significantly higher than that of the specimen with ITZs. The maximum tensile stress error is $8.1 \%$, and the corresponding strain error is $36 \%$. Liu et al. obtained a similar result in [10]. This shows that the presence of A-M ITZs and R-M ITZs decreases the strength and accelerates the damage evolution and failure of the test piece. The fracture position and total dissipated energy will also change with the presence of A-M
ITZs and R-M ITZs. The crack pattern with a constant A-M ITZs and R-M ITZs will be closer to that of the tested specimen that can be obtained from Figure 9. As shown in Figure 10, at the initial fracture stage, the total dissipated energy of the model with A-M ITZs and R-M ITZs will be slightly higher than other models, while, at the final fracture stage, the model with A-M ITZs and R-M ITZs will be the lowest one than other models. The dissipated energy of specimens that only contain A-M ITZs is lower than the specimen with R-M ITZs. It indicates that the presence of A-M ITZs and R-M ITZs will make the specimen much weaker, and the dissipated energy will decrease. Besides, the R-M ITZs have a more significant impact on the fracture energy.

It can be concluded that mesoscale models neglecting A-M ITZs and R-M ITZs for uniaxial tensile simulation do not provide reliable predictions for the stress-strain behavior. Furthermore, it can be concluded from Figure 8 that 


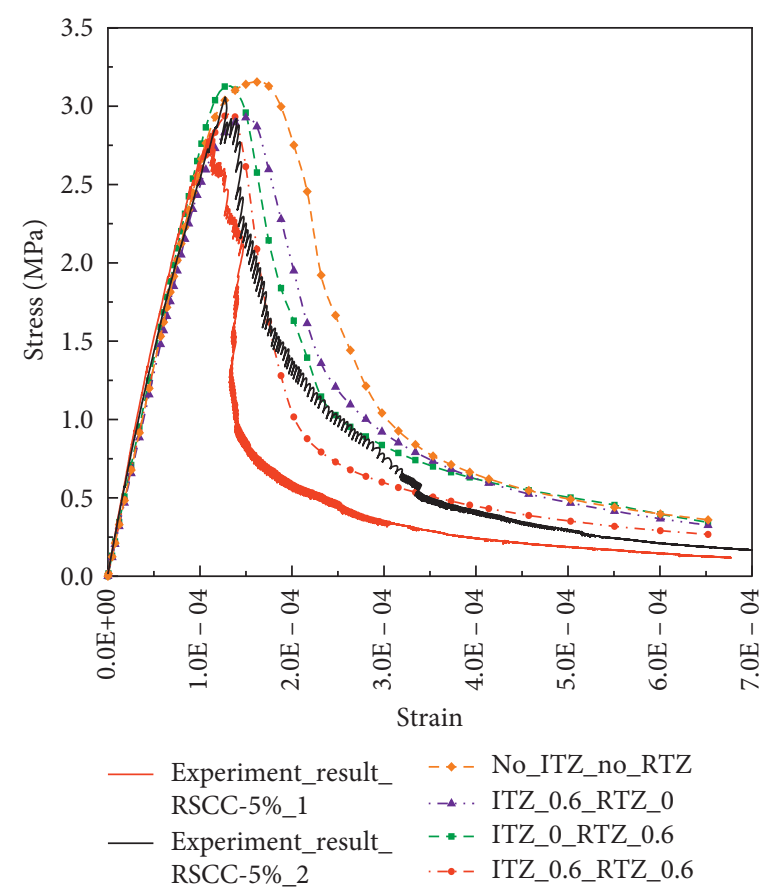

FIgURE 8: Stress-strain curves of the A-M ITZs and R-M ITZs existence study.

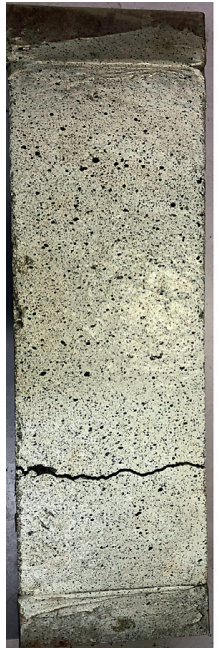

(a)

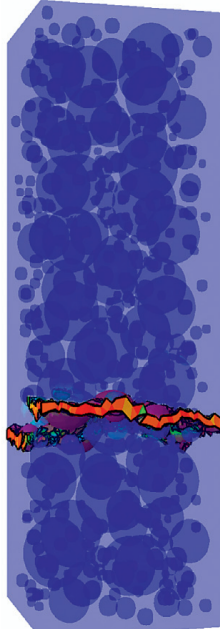

(b)

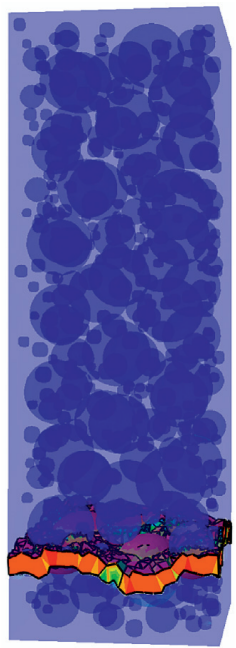

(c)

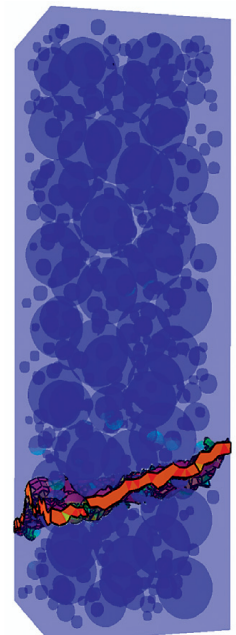

(d)

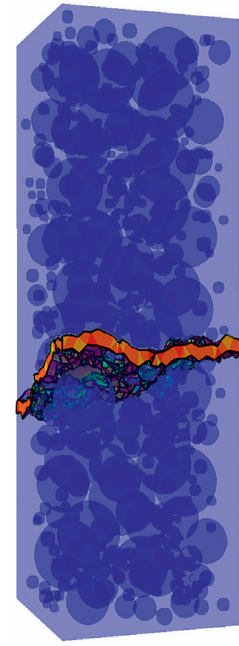

(e)

FIGURE 9: Crack patterns of the A-M ITZs and R-M ITZs existence study. (a) Test result. (b) ITZ_0.6_RTZ_0.6. (c) ITZ_0.6_RTZ_0. (d) ITZ_0_RTZ_0.6. (e) ITZ_0_RTZ_0.

the presence of A-M ITZs has a more significant effect on the strength than the presence of R-M ITZs. However, R-M ITZs have a high impact on fracture energy. It is expected that R-M ITZs is the weakest part of a specimen. If there are no R-M ITZs in a test piece, the failure rate will decrease, and the fracture energy will increase. When a mesoscale model has both ITZ types, the numerical simulation results are very close to the test results, indicating that the introduced ITZs in this work are realistic, and the model results are in closest agreement with the experimental data. It is then justified to explore the effects of other mechanical properties of RSCC constituents in the subsequent sections.
4.1.2. Effect of A-M ITZs Thickness. To explore the A-M ITZs thickness effect on the fracture properties, four different models were generated. These have the same geometry, but A-M ITZs thickness is taken as $0 \mathrm{~mm}, 0.6 \mathrm{~mm}, 0.8 \mathrm{~mm}$, and $1 \mathrm{~mm}$, respectively. The thickness of R-M ITZs is $0.6 \mathrm{~mm}$ for all models in this section. The aggregate volume fraction is $30 \%$, rubber particle volume fraction is $5 \%$, and porosity is $1 \%$ of all models in this section. The simulation result is shown in Figure 8. As can be seen from the Figure 11, if the A-M ITZs is not included in the mesoscale model, the strength of the specimen will be significantly higher than the experimental result, indicating that the presence of A-M ITZ 


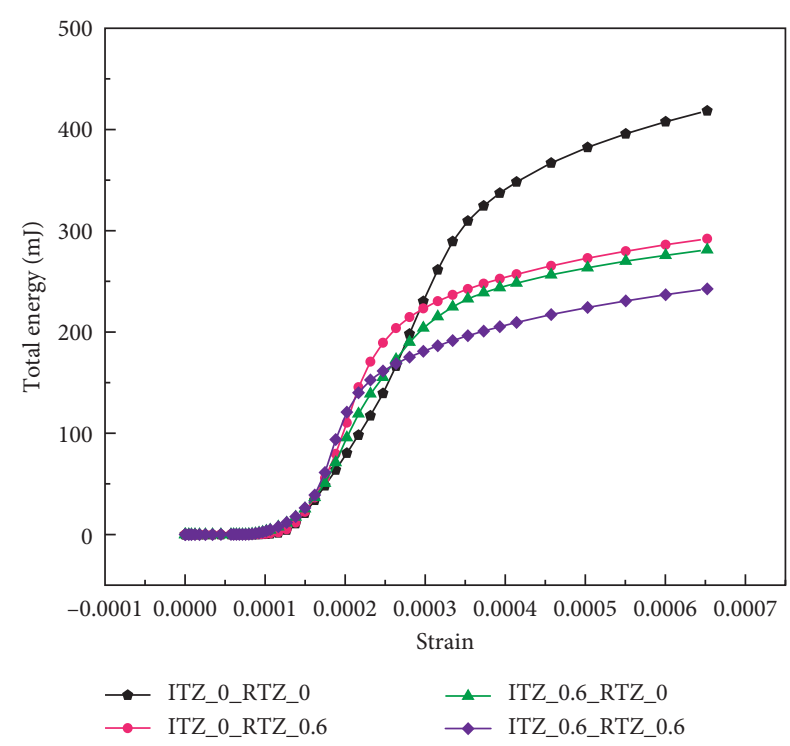

Figure 10: Energy-strain curves of the A-M ITZs and R-M ITZs existence study.

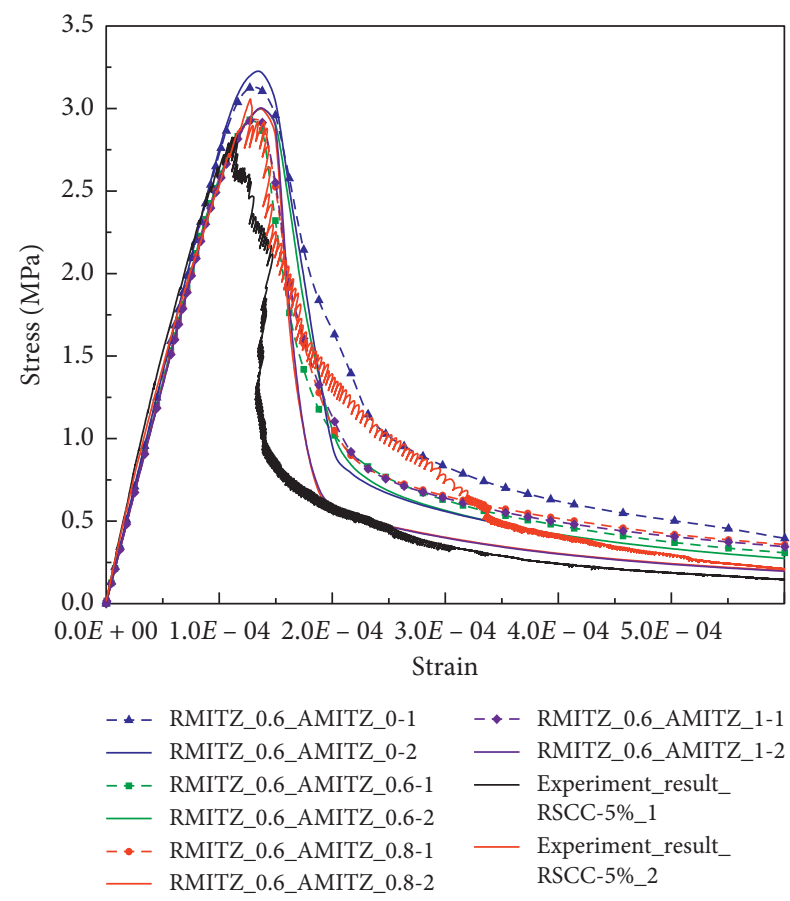

FIGURE 11: Stress-strain curves of varying thickness A-M ITZs models.

is a key factor affecting the strength of the specimen, which is consistent with the conclusion obtained in Section 4.1.1. There is a small difference between the models with a thickness of $0.6 \mathrm{~mm}, 0.8 \mathrm{~mm}$, and $1 \mathrm{~mm} \mathrm{A-M} \mathrm{ITZs,} \mathrm{but} \mathrm{all}$ results are close to the experimental one. This outcome indicates that the thickness $0.6 \mathrm{~mm}$ of A-M ITZs can meet the calculation requirements.

4.1.3. Effect of R-M ITZs Thickness. Four models were generated to explore the R-M ITZs thickness effect on the fracture properties. These have the same geometry as the models in Section 4.1.1, but the R-M ITZs thickness is varied as $0 \mathrm{~mm}, 0.6 \mathrm{~mm}, 0.8 \mathrm{~mm}$, and $1 \mathrm{~mm}$, respectively. The thickness of A-M ITZs is $0.6 \mathrm{~mm}$ for all models in this section. Two realizations of each type were used for numerical simulations. The stress-strain curves obtained are shown in Figure 12. It can be seen that if the RTZ is not included in the mesoscale model, the strength of the specimen changes insignificantly. However, the strain corresponding to the peak stress increases significantly, and the toughness of the specimen is enhanced. It shows that R-M ITZs is the most vulnerable part of the whole specimen, apart from voids. If there are no R-M ITZs in the specimen, the failure rate of the specimen will be reduced substantially. Such an outcome is quite different from the test results indicating that the R-M ITZs should be included in the numerical simulation. The simulation results with different thickness R-M ITZs are not significantly different, and all are close to the experimental results, indicating that the effect of R-M ITZs thickness within the studies range is minimal. The thickness of $0.6 \mathrm{~mm}$ can meet the requirements of calculation accuracy.

Therefore, it can be obtained from the above study on the thickness of ITZs: in the mesoscale simulation of rubberized self-compacting concrete, it is necessary to separately model A-M ITZs and R-M ITZs. Moreover, when the thickness of both ITZs is $0.6 \mathrm{~mm}$, it can not only meet the requirements of simulation accuracy but also make the number of elements of the mesoscale model within a calculable range. It is recommended that the researcher choose $0.6 \mathrm{~mm}$ as the thickness of A-M ITZs and R-M ITZs for mesoscale modelling.

4.2. Porosity Effect. The relationship between porosity and specimen strength was studied using specimens of dimension $50 \mathrm{~mm} \times 50 \mathrm{~mm} \times 150 \mathrm{~mm}$. In all specimens, the aggregate content was $30 \%$. The differences between different models were the rubber content and porosity: rubber particle volume fractions were $0,5 \%, 10 \%$, and $15 \%$ respectively, and the porosity of each model with given rubber particle content was $0,1 \%, 2 \%$, and $5 \%$, respectively. Twenty realizations were simulated for each model type. The mean stress-strain curves of specimens with different porosity under uniaxial tension are shown in Figure 13. For each specimen type with a specific rubber particle content, the strength decreases as the porosity increases.

It can be seen from Figure 13, for ordinary self-compacting concrete, there are no pores in the mesoscale model, the elastic modulus and strength are significantly greater than the test result, and the simulation result of the mesoscopic models with a porosity of $1 \%$ and $2 \%$ are close to the test result; when the porosity of the mesoscopic model is $1 \%$ or $2 \%$, the simulated results are close to those of the uniaxial tensile test; for a specimen with a rubber content of $10 \%$, when the mesoscopic model does not contain pores, the strength is close to the test result, but the elastic modulus is significantly greater than the test result, and the simulated strength and elastic modulus are in the range of the two test 


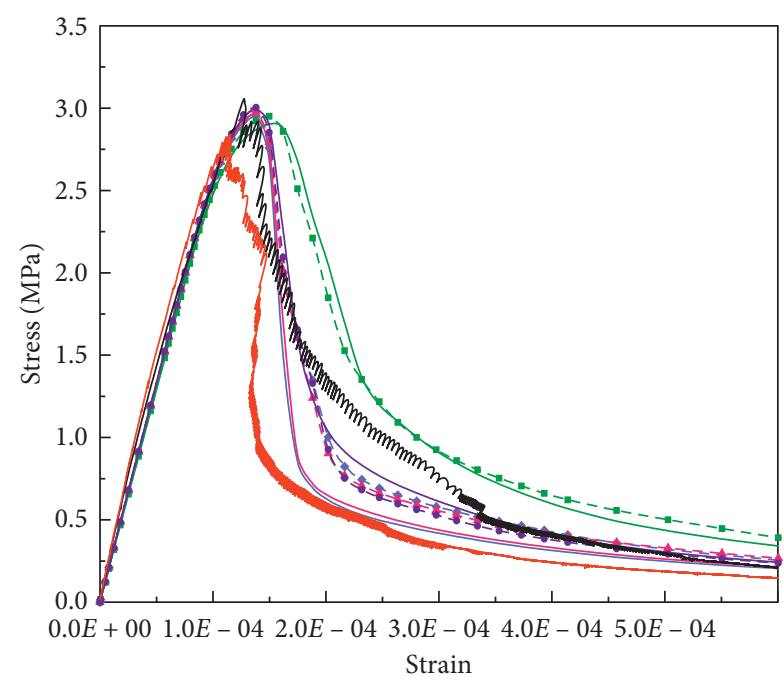

$$
\begin{array}{lll}
- \text { AMITZ_0.6_RMITZ_0-1 } & - \text { AMITZ_0.6_RMITZ_1-1 } \\
--- \text { AMITZ_0.6_RMITZ_0-2 } & -- \text { AMITZ_0.6_RMITZ_1-2 } \\
- \text { AMITZ_0.6_RMITZ_0.6-1 } & - \text { Experiment_result_ } \\
-\bullet \text { AMITZ_0.6_RMITZ_0.6-2 } & \text { RSCC-5\%_1 } \\
- \text { AMITZ_0.6_RMITZ_0.8-1 } & \text { Experiment_result_ } \\
-\_ \text {AMITZ_0.6_RMITZ_0.8-2 } & \text { RSCC-5\%_2 }
\end{array}
$$

FIGURE 12: Stress-strain curves of varying thickness R-M ITZs models.

specimens when the mesoscopic model is with a porosity of $1 \%$ and $2 \%$, while the elastic modulus of the mesoscale model with a porosity of $5 \%$ is significantly smaller than the test result; the strength and elastic modulus of the specimen with a rubber content of $15 \%$ and a porosity of $2 \%$ are close to the test results, while the strength and elastic modulus of the specimen with a porosity of $1 \%$ and 0 are significantly greater than the test results. The strength of a specimen with a porosity of $5 \%$ is significantly lower than the test result; a comprehensive comparison of the mesoscale simulation results of all different rubberized self-compacting concrete shows that if the mesoscale model used in this paper is used to study the mechanical behavior of rubber self-compacting concrete, the pores should be modeled separately in the model, and the results obtained with a porosity of $2 \%$ are the closest to the actual test results.

Wang at al. [33] proposed a power law for the strength porosity relations, similar to the one for compression strength in cement paste suggested by Powers [34]. A similar power law is proposed for the relationship of rubberized concrete strength and porosity in this study:

$$
\sigma=\sigma_{0}^{n}(1-p)^{m}
$$

where $\sigma_{0}^{n}$ is the specimen strength without voids, $p$ is the porosity, $m$ is an empirical coefficient, and $n$ classifies the concrete with different rubber contents. Specifically, when the rubber content is $0, n$ is 1 , when the rubber content is $5 \%$, $n$ is 2 , when the rubber content is $10 \%, n$ is 3 , and when the rubber content is $15 \%, n$ is 4 . For each specimen with different rubber contents, the value of $m$ is different. The proposed law and the numerical results are shown in Figure 14.
4.3. Crack Propagation and Fracture Pattern. Figures 15 and 16 present damage development and typical failure patterns under uniaxial tension. It can be seen that samples can develop type I (failure by one main crack) as well as type II (failure by more than one main crack) fracture patterns. As discussed in [30, 31], type II and type I failures may occur in the uniaxial tension simulation where the prepeak response and strength are similar, but the postpeak responses are substantially different. If a type I crack occurs, the softening stage is relatively more rapid compared to a type II cracking mode. From the stress-strain responses shown in Figure 17, it can be seen that the postpeak softening for the type IIcracked sample is more graceful than that for type I. Figure 18 shows energy dissipations in type I and type II cracking modes where DMD and PD correspond to damage and plastic dissipation energy. As can be seen from Figure 18, the plastic dissipation energy of the type II crack is much higher than type I due to the dominant fracture is a shear fracture in the type II crack, and much more energy will be consumed by shear fractures. However, the damage dissipation energy of the type II crack is a little bit lower than type I, indicating that the damage level of the type II crack is not as worse as the type I crack.

In the two samples, many microcracks initiate in the early stage of loading on the R-M ITZs and A-M ITZs due to their lower strength than mortar. Figures 15(a) and 16(a) show two cracking states at peak stress. It can be seen that there are no obvious macrocracks formed in either of the two cracking modes. The fracture development of the postpeaks $0.6 p$ and $0.4 p$ is shown in Figures 15(b), 15(c), 16(b), and 16(c). With the increase of the load, interfacial cracks between rubber particles and mortar and aggregate and mortar continue to develop and eventually coalesce into the main crack(s) through the mortar. It should be noted that in Figures 15(b), 15(c), 16(b), and 16(c), microscopic cracks still exist, but their damage is much smaller than that of macroscopic cracks to be visible in either of the two fracture patterns.

Rabczuk [35, 36] proposed a meshfree method for arbitrary evolving cracks, which has great advantages in simulating the cracking process of the specimen, and it has been successfully applied to the cracking of reinforced concrete structures [37]. If this method can be introduced into the mesoscopic model proposed in this paper, the cracking process of the specimen under uniaxial tension can be simulated more accurately.

4.4. Rubber Particle Size Effect. As mentioned in the introduction, there are some arguments about the relationship between rubber size and strength. The results obtained by Fattuhi and Crark [5] and Ali et al. [6] indicated that concrete containing rubber with fine grading had lower strength than that containing coarse rubber. Nevertheless, Eldin and Senouci [3] and Topcu [2] obtained the opposite effect. The controversy still exists, and all scholars can accept no common conclusion. In this section, two mesoscale models are used: in the first one, sand is replaced with fine rubber particles by volume, and in the second one, aggregates are replaced by coarse rubber particles by volume. The 


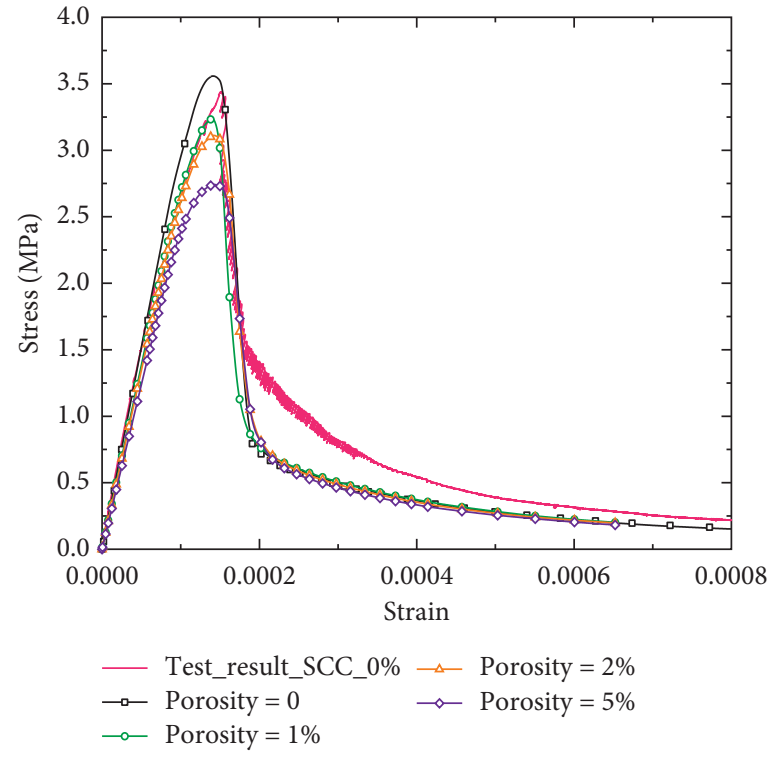

(a)

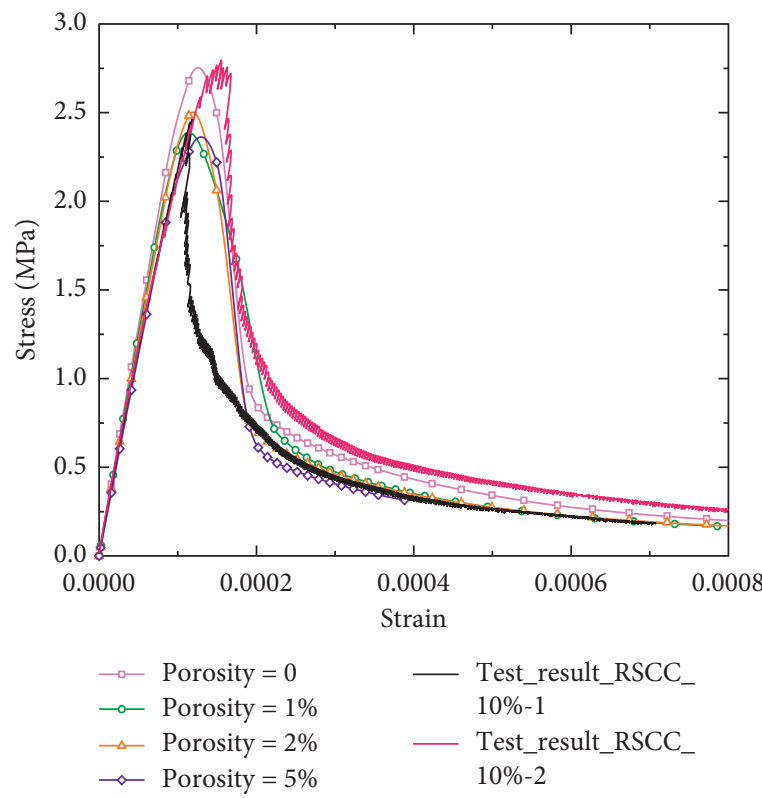

(c)

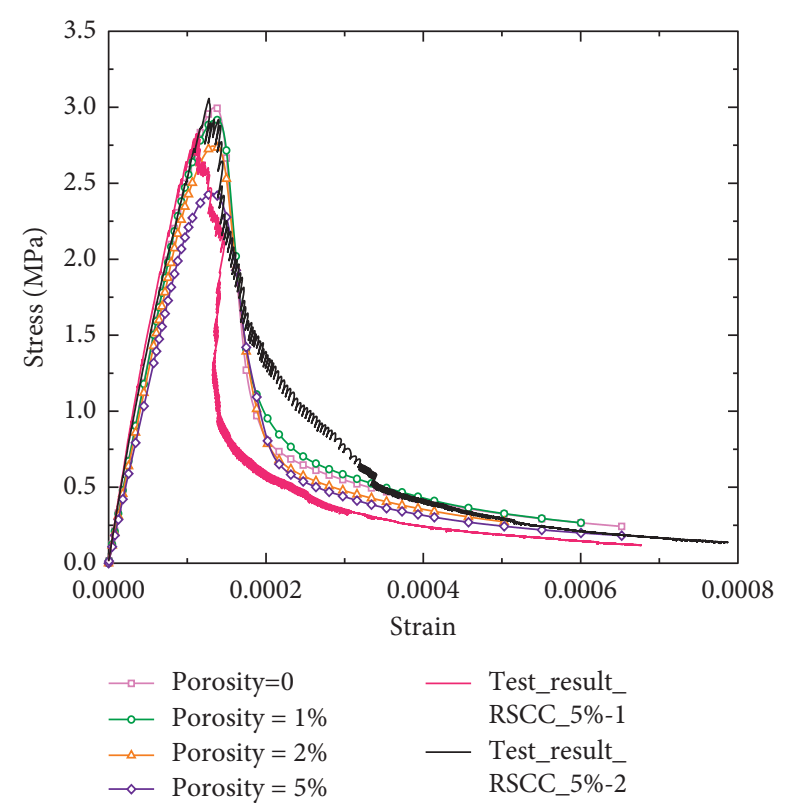

(b)

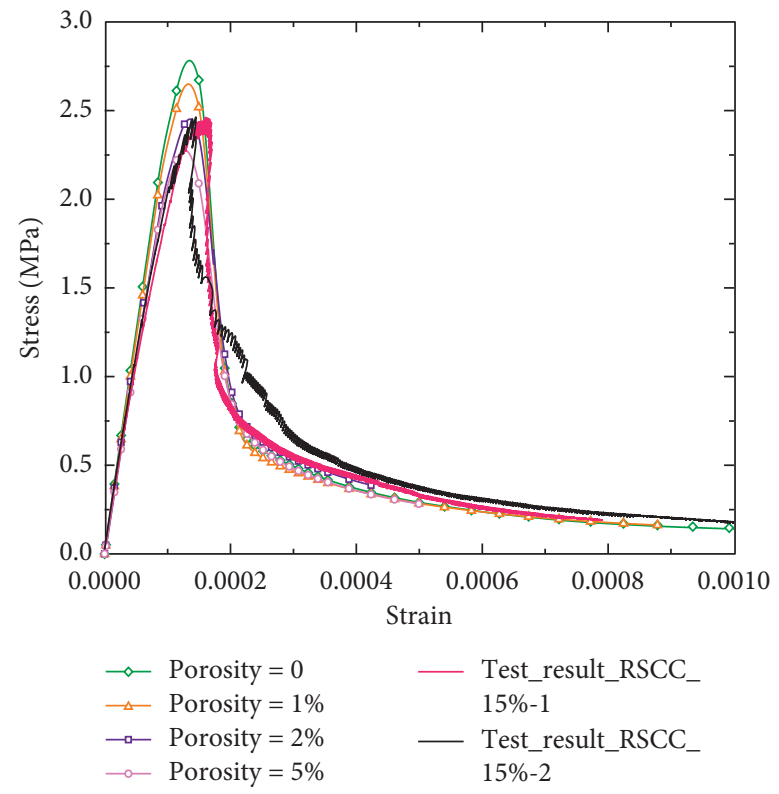

(d)

FIGURE 13: Stress-strain curves of varying porosity models. (a) Specimen with no rubber. (b) Specimen with 5\% rubber. (c) Specimen with $10 \%$ rubber. (d) Specimen with 15\% rubber.

replaced volumes are $5 \%, 10 \%$, and $15 \%$, respectively. The aggregate volume is $30 \%$, and the porosity is $1 \%$; thickness of A-M ITZs and R-M ITZs is $0.6 \mathrm{~mm}$ for all mesoscale models. For each model type, twenty realizations are generated and simulated to get a statistical result for the rubber size effect. The geometry of the two types of models is shown in Figure 19 . The rubber volume of these models is $5 \%$.

4.4.1. Rubber Particles Replacing Fine Aggregates by Volume. Mesoscale models with different rubber volume fractions were used to simulate uniaxial tension and obtain the relationship between strength and fine rubber volume fraction. The rubber volume was $5 \%, 10 \%$, and $15 \%$, respectively. The coarse aggregate content in all the samples remained at $30 \%$. The simulation parameters were kept consistent with Table 3 . The strength of the specimen without rubber was kept consistent with the experimental result of SCC. The stress-strain curves of the simulation result are shown in Figure 20. The stress is the total vertical reaction force of all the top boundary nodes that divides by the specimen cross-section area. As can be seen from Figure 18, the stress-strain curves from different realizations have small differences. As the rubber content increases, the 


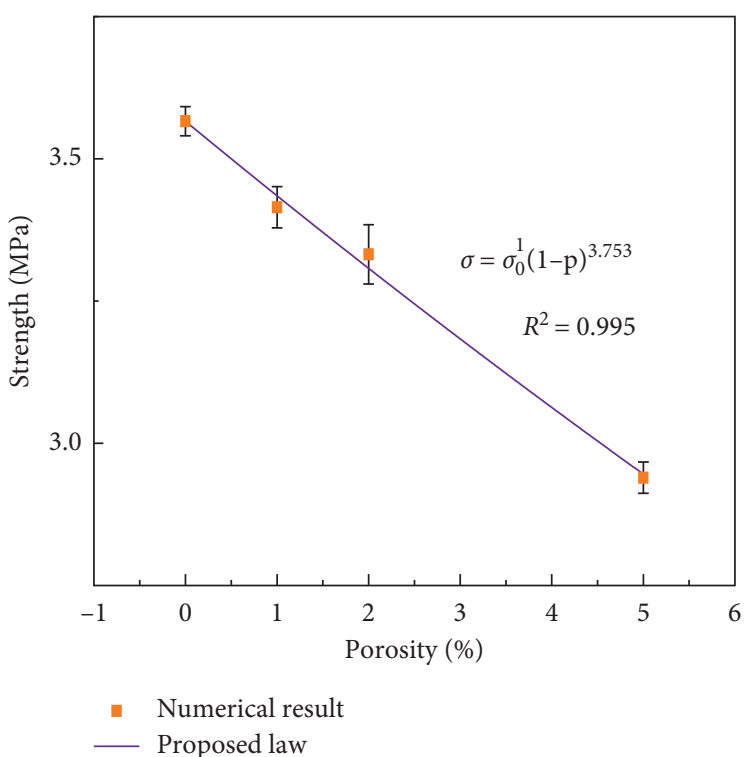

(a)

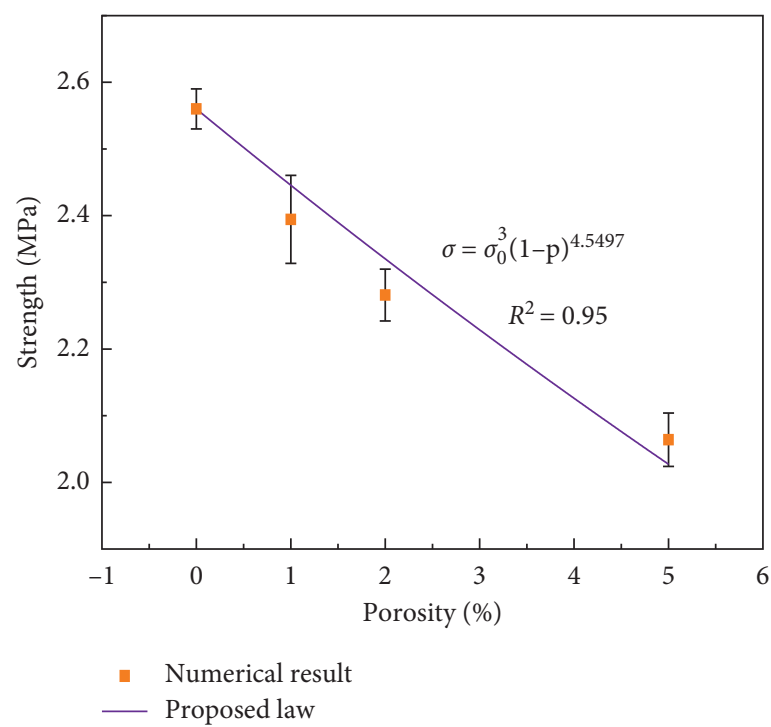

(c)

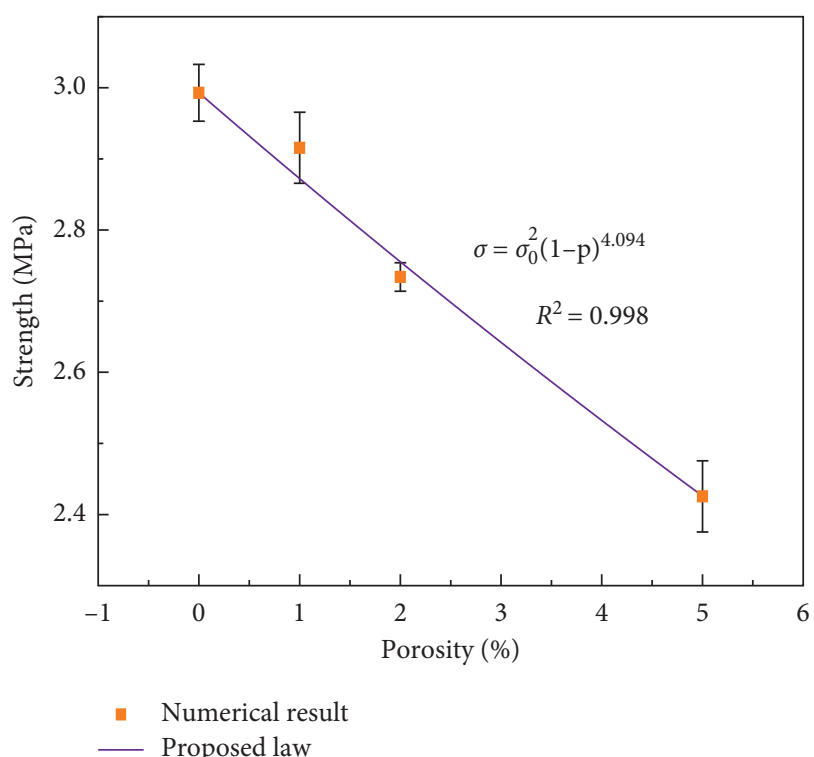

(b)

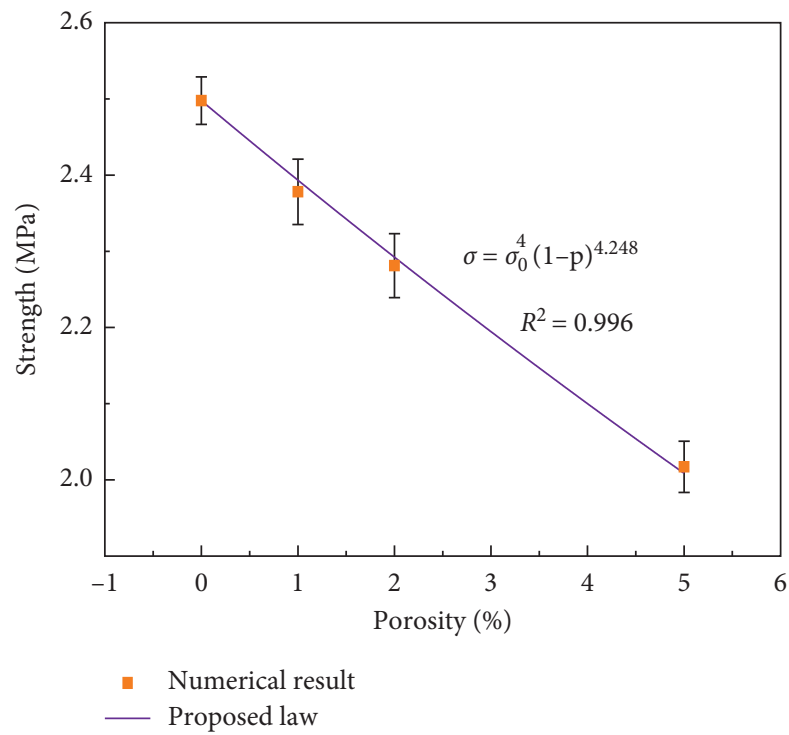

(d)

FiguRe 14: Effect of porosity on strength for models with different rubber contents $\left(P_{\text {agg }}=30 \%\right)$. (a) Rubber content $=0$. (b) Rubber content $=5 \%$. (c) Rubber content $=10 \%$. (d) Rubber content $=15 \%$.

average maximum stress decreases, and the postpeak curves for all samples decrease more rapidly, indicating that specimens with fine rubber replacing sand have a high failure rate and low fracture toughness.

Toutanji [7] found that the relationship between strength reduction and the volume of rubber aggregate is not linear through experimental studies. Based on the above simulation results, it is found that the following quadratic function can well describe the influence of the volume fraction of rubber particles on the strength of all specimens through curve fitting:

$$
\begin{aligned}
y & =40.614 x^{2}-11.729 x+3.510, \\
R^{2} & =0.992 .
\end{aligned}
$$

The relationship between the proposed law and the numerical result is shown in Figure 21.

4.4.2. Rubber Particles Replacing Coarse Aggregates by Volume. To obtain the relationship between the specimen strength and the volume fraction of coarse rubber particles, models with different volume fraction coarse rubber particles replacing the coarse aggregate were analysed. Three sets of models with $5 \%, 10 \%$, and $15 \%$ rubber content were used. To maintain a constant total coarse aggregate volume of $30 \%$, the corresponding aggregate volume of the specimens was $26 \%$, $22 \%$, and $18 \%$, respectively. Twenty realizations were generated and analysed for each model type. Since the volume fraction of fine aggregates in the model was not changed, the mortar 


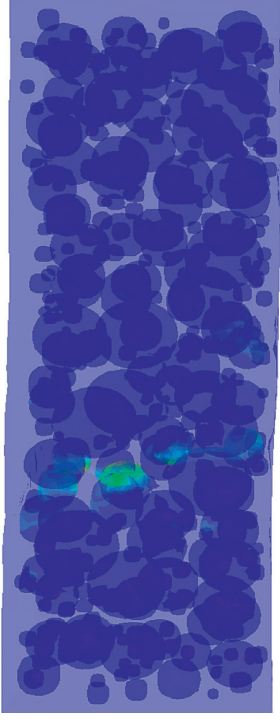

(a)

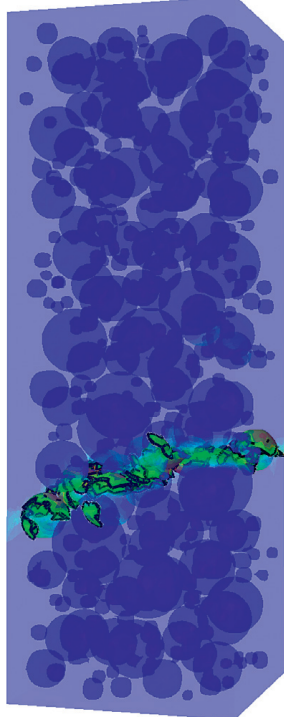

(b)

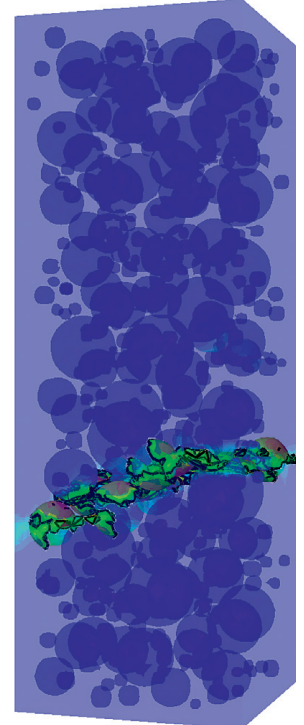

(c)

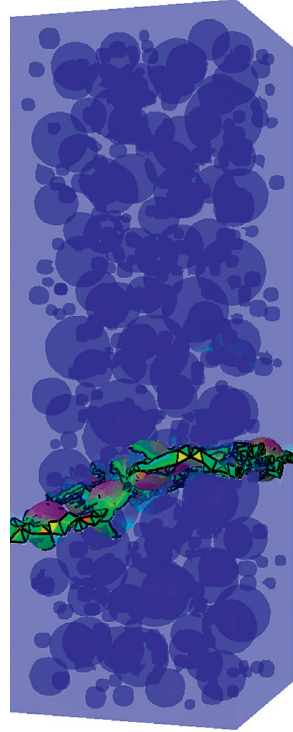

(d)

Figure 15: Crack development process of the type I crack ( $p$ is the peak stress; $0.8 p, 0.6 p$, and $0.4 p$ are all corresponding postpeak loading phases). (a) p. (b) $0.8 p$. (c) $0.6 p$. (d) $0.4 p$.

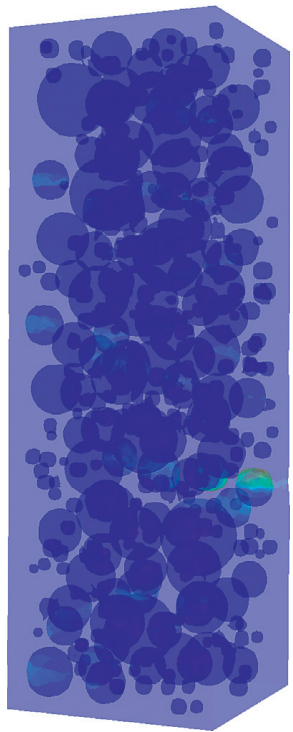

(a)

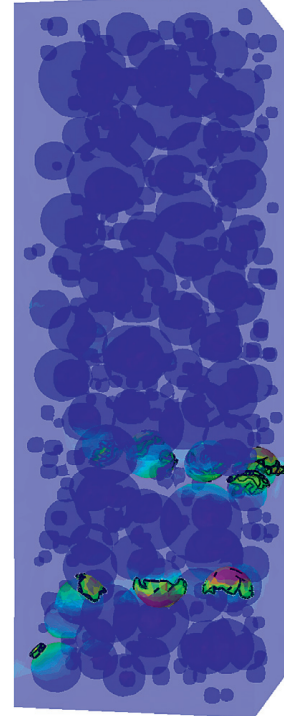

(b)

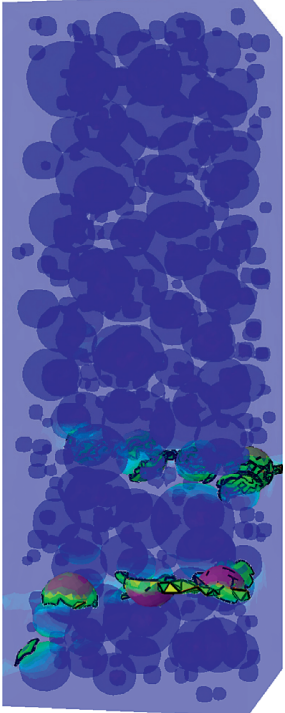

(c)

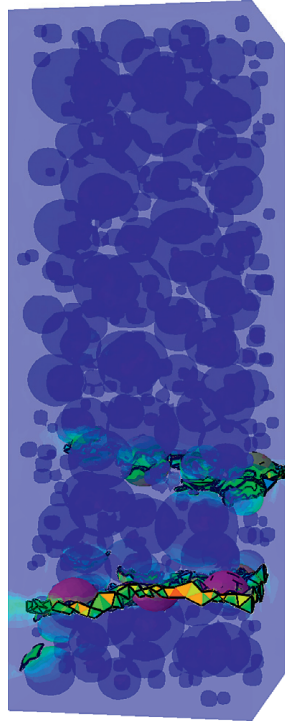

(d)

FIGURE 16: Crack development process of the type II crack ( $p$ is the peak stress; $0.8 p, 0.6 p$ and $0.4 p$ are all corresponding postpeak loading phases). (a) p. (b) $0.8 p$. (c) $0.6 p$. (d) $0.4 p$.

parameters of the rubberized concrete were not changed, consistent with pure mortar. The numerical simulation parameters are shown in Table 4 . Because in this kind of mesoscale model, rubber particle was used to replace aggregate rather than sand, the parameters of mortar were kept constant in all the generated models in this section. The stress-strain curves of the test results of each group are shown in Figure 22.
As can be seen from Figure 22, the prepeak stress-strain curves are identical. However, the postpeak stress-strain curves of different specimens are quite different. Some curves show more graceful softening because type II cracks appear in those specimens. As the rubber content increases, the average maximum stress decreases, i.e., the incorporation of rubber particles reduces the strength of the concrete. 


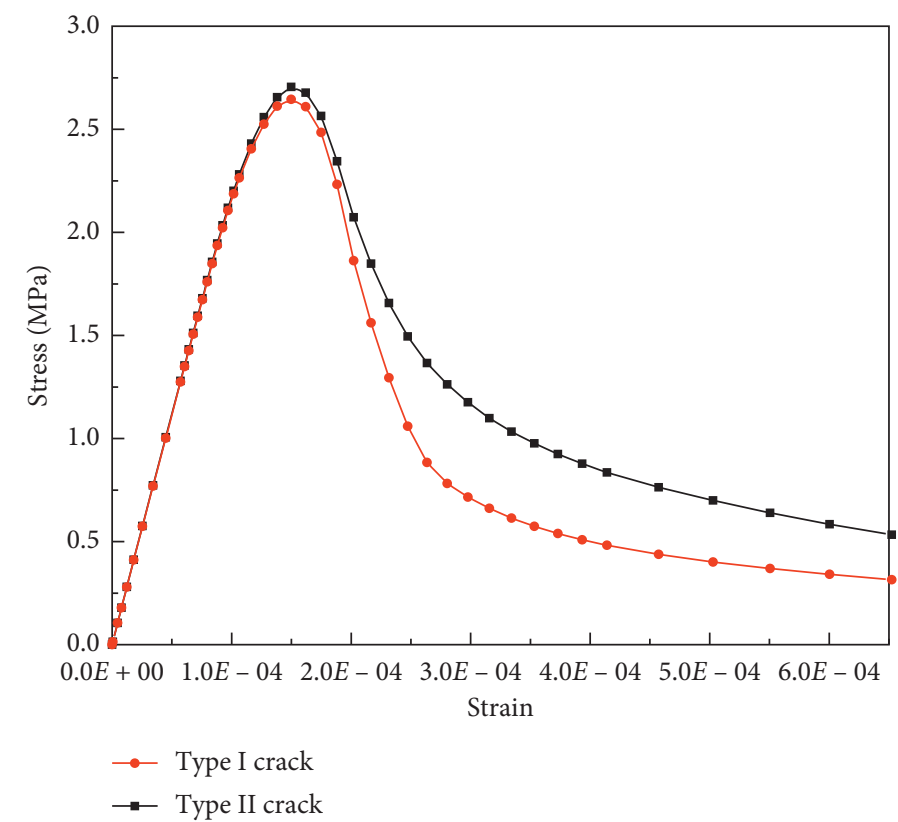

Figure 17: Stress-strain curves of the type I crack and type II crack.

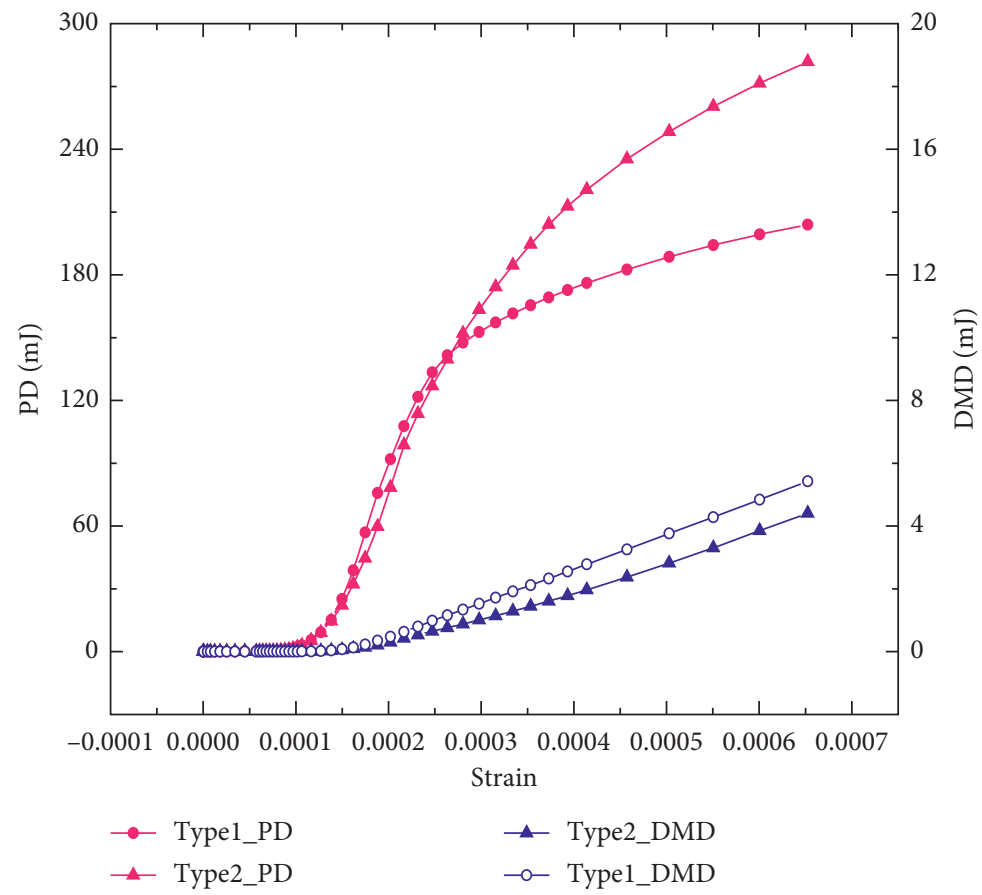

FIGURE 18: Energy-strain curves of the type I crack and type II crack.

Based on the simulation results, it is found that the following quadratic function can well describe the influence of rubber particle volume fraction on the strength of all specimens:

$$
\begin{aligned}
y & =52.172 x^{2}-15.625 x+3.536, \\
R^{2} & =0.996
\end{aligned}
$$



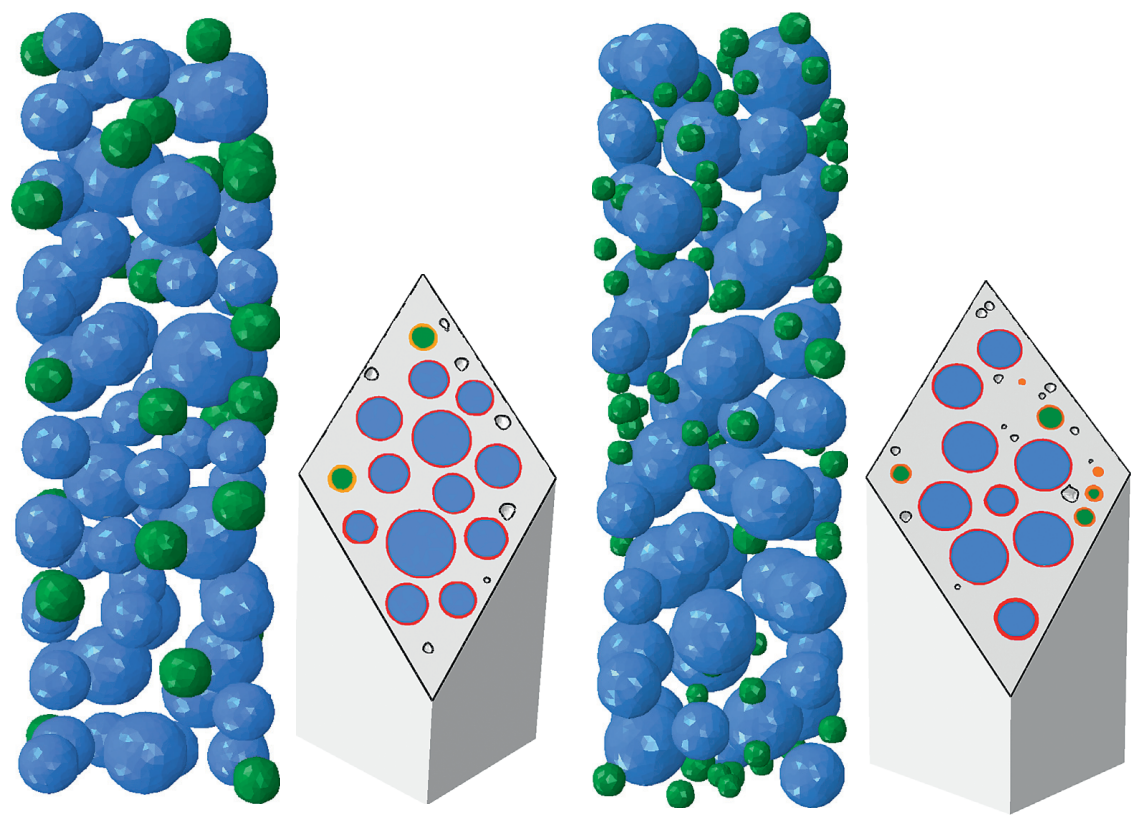

Aggregate

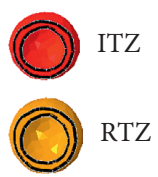

Rubber particle

(a)

(b)

FIGURE 19: Compositions of the mesoscale model with rubber particle replacing coarse aggregate and sand. (a) Rubber particle replacing the aggregate model. (b) Rubber particle replacing the sand model.

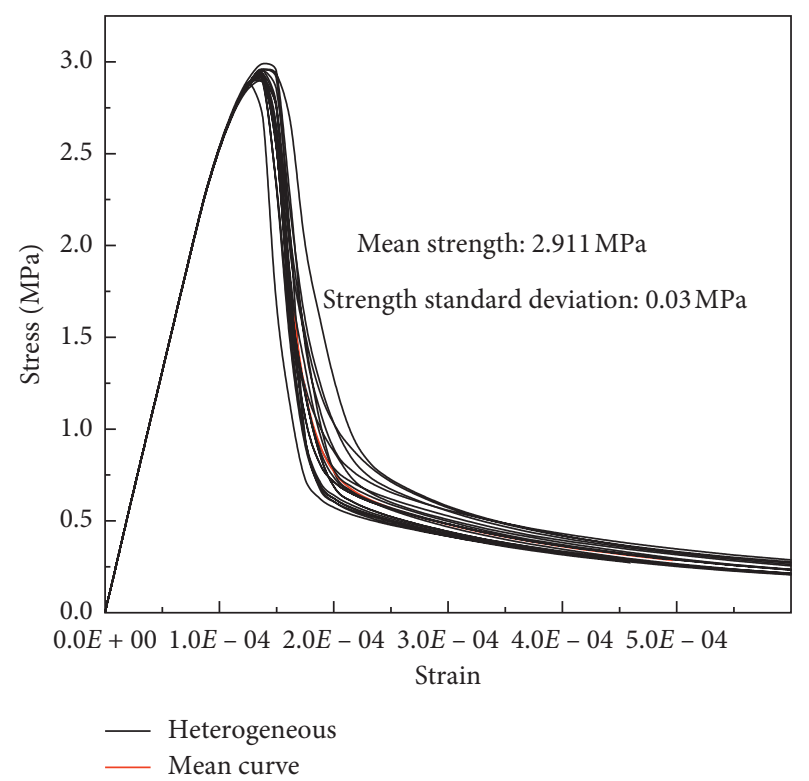

(a)

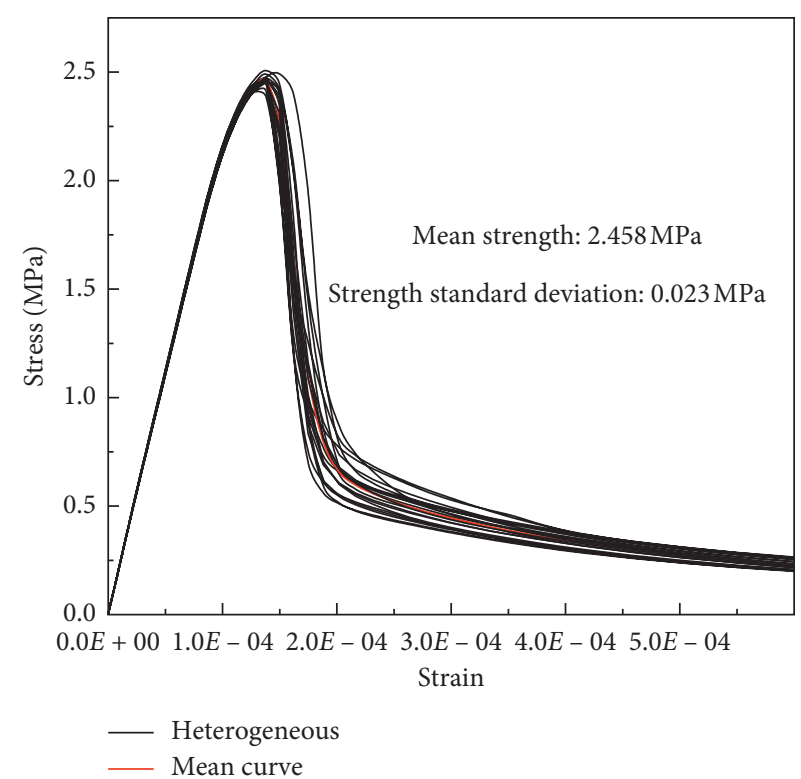

(b)

Figure 20: Continued. 


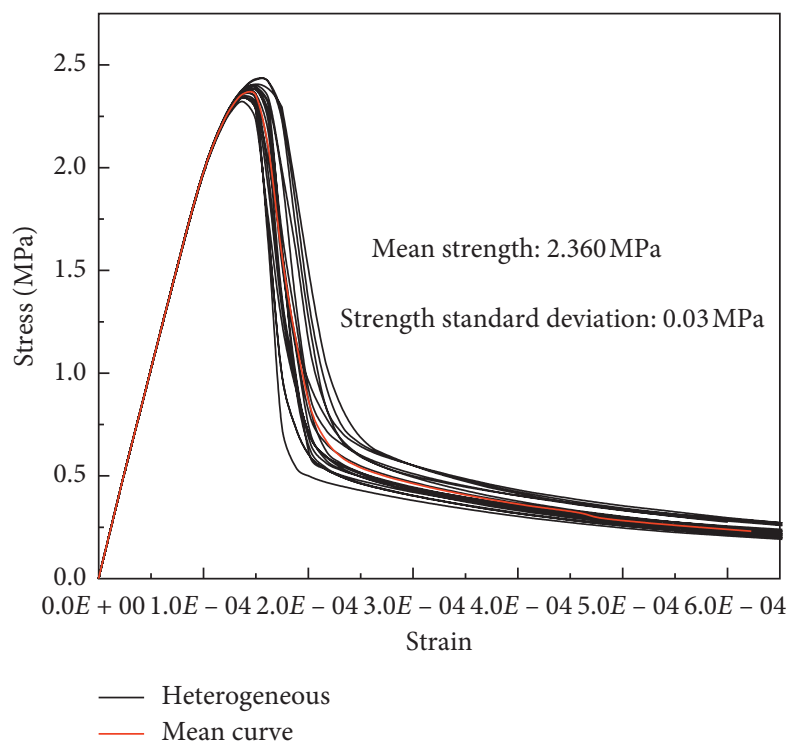

(c)

FiguRE 20: Stress-strain curves of rubber replacing sand models. (a) Rubber replace 5\% sand. (b) Rubber replace 10\% sand. (c) Rubber replace $15 \%$ sand.

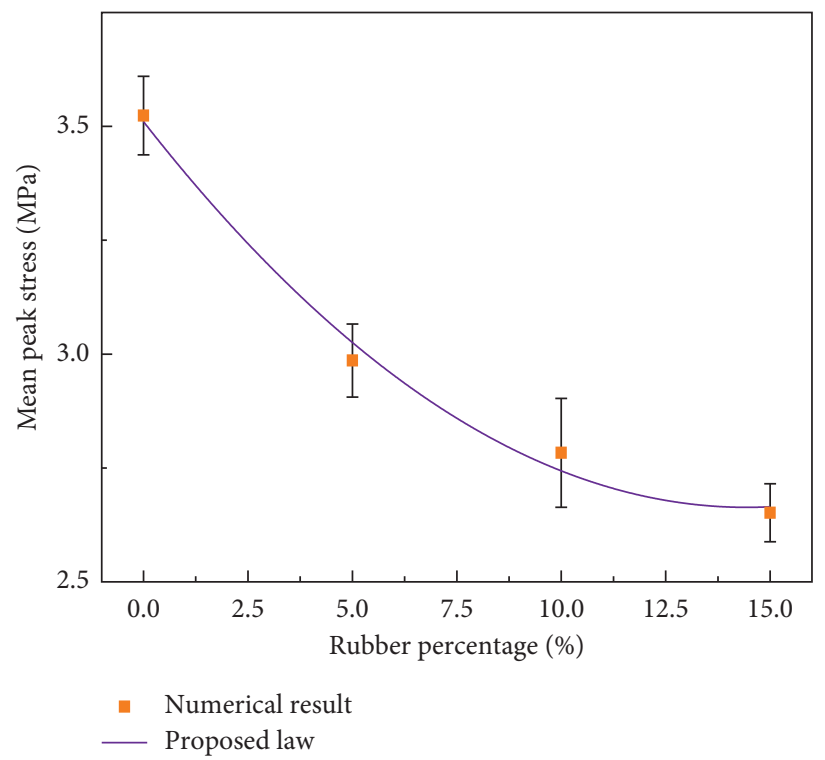

FiguRE 21: Effect of rubber volume fraction on peak stress for rubber replacing sand models.

TABLE 4: Material parameters for the rubberized concrete mesoscale model with rubber replacing aggregate.

\begin{tabular}{lccccc}
\hline & Tensile strength $(\mathrm{MPa})$ & Compressive strength $(\mathrm{MPa})$ & Young's modulus $(\mathrm{GPa})$ & Poisson's ratio & Density $\left(\mathrm{kg} / \mathrm{m}^{3}\right)$ \\
\hline Coarse aggregate & - & - & 40 & 0.2 & 2600 \\
Rubber particle & - & - & 7 & 0.4 & 1050 \\
A-M ITZ & 3 & 45 & 21 & 0.2 & 1800 \\
R-M ITZ & 1.5 & 25 & 2.5 & 0.2 & 1500 \\
Mortar & 4.5 & 60 & 28 & 0.2 & 2200 \\
\hline
\end{tabular}




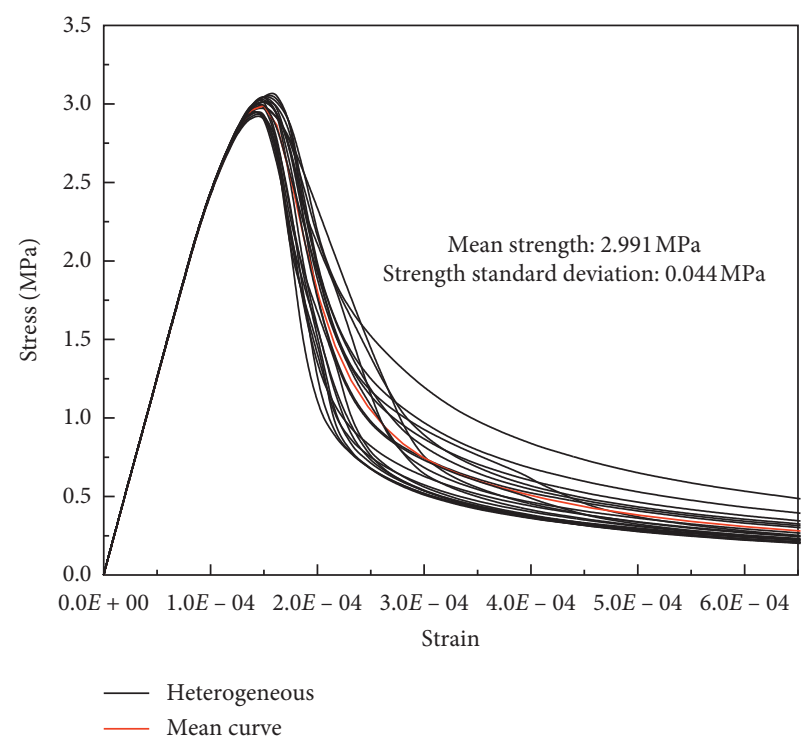

(a)

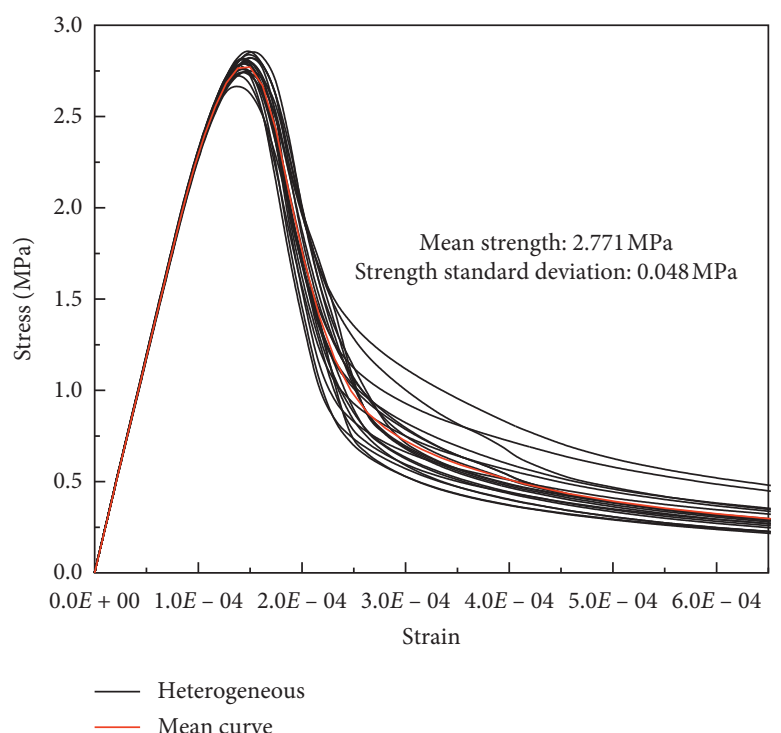

(b)

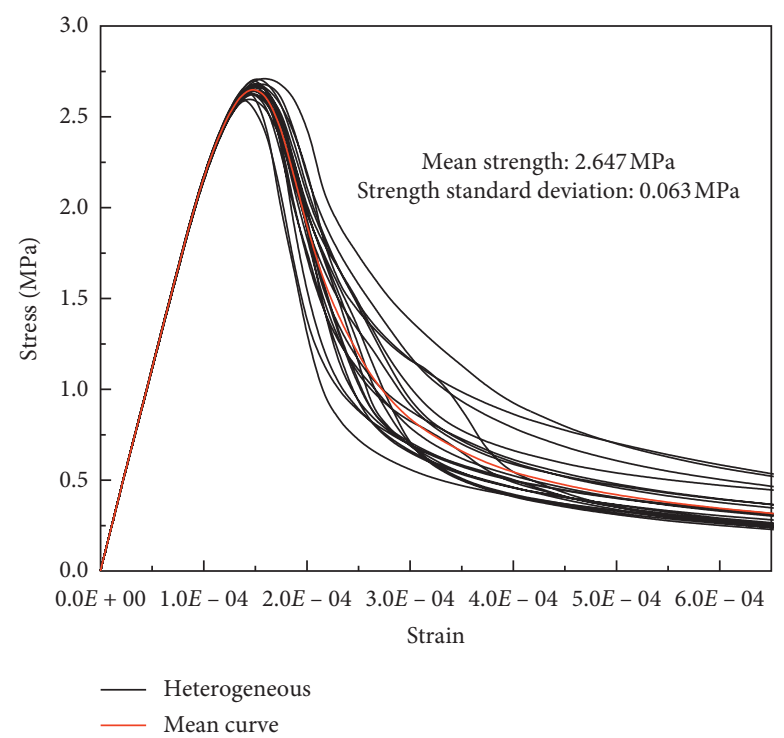

(c)

FiguRE 22: Stress-strain curves of rubber replacing aggregate models. (a) Rubber replace 5\% aggregate. (b) Rubber replace $10 \%$ aggregate. (c) Rubber replace $15 \%$ aggregate.

The relationship between the proposed law and the numerical result is shown in Figure 23.

The average stress-strain curves from samples with rubber replacing aggregates and rubber replacing sand are shown together in Figure 24. It can be seen from the figure that if the coarse rubber particles are used to replace the aggregate, the strength of the test piece may be larger than the one replaced by fine rubber particles, which agrees with the conclusion obtained by Fattuhi and Clark [5] and Ali at al. [6]. With the increase of the replacement volume, the strength difference becomes more considerable. The toughness of specimens with aggregates replaced by coarse rubber is higher than that of specimens with sand replaced by fine rubber by the same volume. This results from the lower failure rates of the models with coarse rubber than those with fine rubber. 


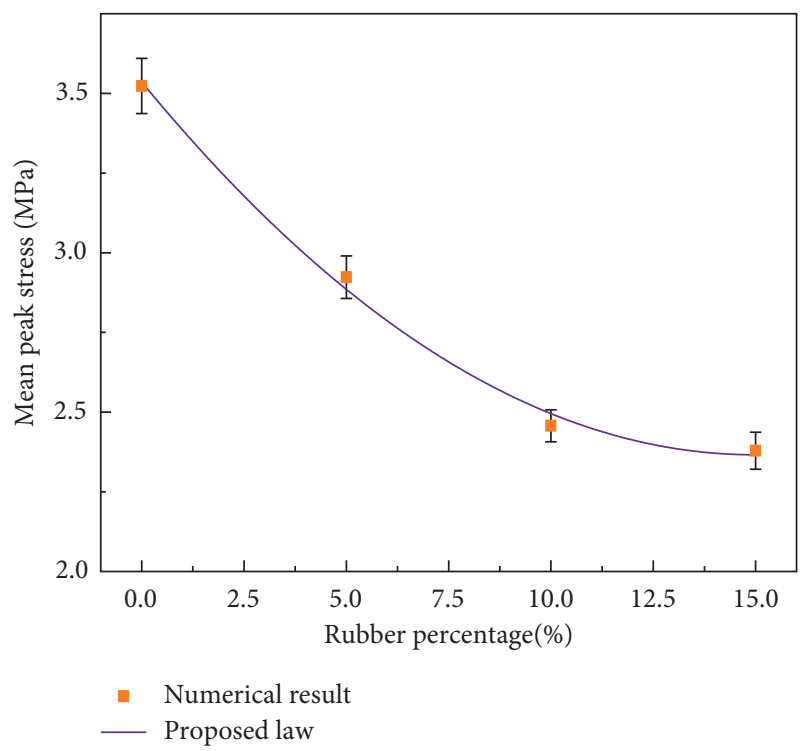

Figure 23: Effect of rubber volume fraction on peak stress for rubber replacing aggregate models.

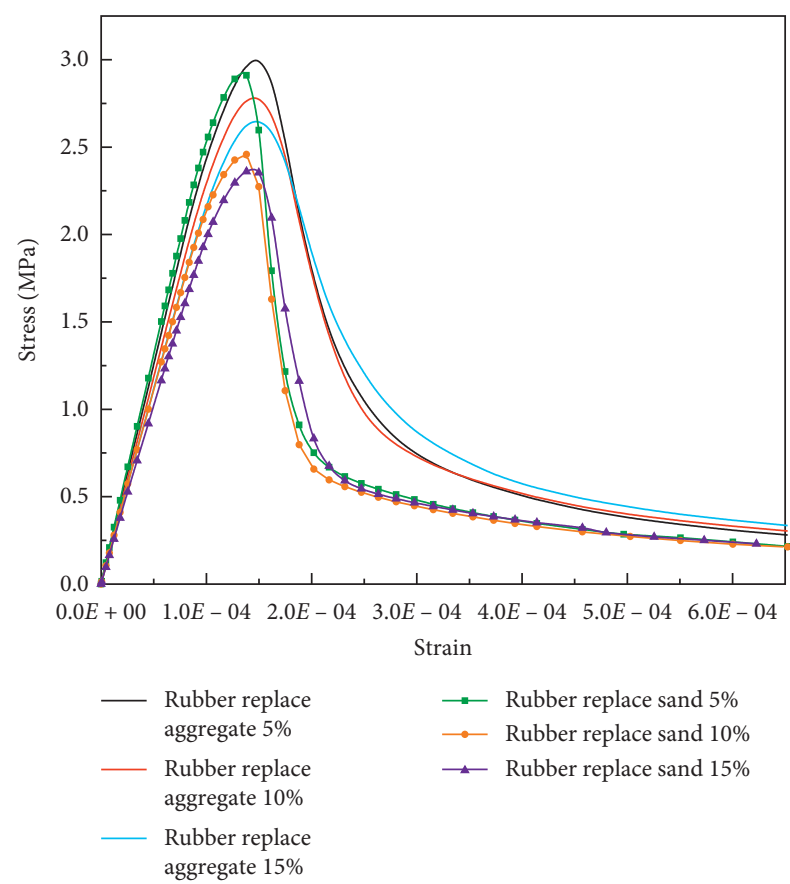

Figure 24: Mean stress-strain curves of rubber replacing sand and aggregate models.

\section{Conclusions}

Modelling and simulation of rubberized concrete under uniaxial tension has been presented. 3D mesoscale models have been developed and validated by comparison of the numerical results with MTS measurements. The effects of mesh size, presence, and thickness of A-M ITZs and R-M ITZs, as well as porosity on the stress-strain curve and crack patterns, have been investigated. The main conclusions are as follows:
(1) The validation stage showed that mesoscale models of rubberized concrete have to contain all relevant phases, as the omission of a phase leads to divergence of simulation results from experimentally measured macroscopic and damage behavior.

(2) Specifically, both A-M and R-M ITZs are essential for the mesoscale model-A-M ITZs have a more significant effect on the strength, while R-M ITZs have a more significant impact on the fracture energy. It is suggested that the researcher choose $0.6 \mathrm{~mm}$ as the thickness of A-M ITZs and R-M ITZs for the mesoscale modelling for it can not only meet the simulation accuracy requirements but also meet the computation efficiency.

(3) Within a computationally acceptable range, the mesh size has little effect on the simulated stressstrain responses, but the emerging crack patterns are sensitive to the mesh size, predominantly because mesh size changes lead to changes in ITZs and voids distributions. It is recommended to choose $0.4 \mathrm{~mm}$ as the mesh size to generate a mesoscale model since the simulation results with $0.4 \mathrm{~mm}$ mesh size will give better agreement with the experiment result.

(4) Porosity has a pronounced effect on the strength, indicating that it should not be ignored in mesoscale models. The mesoscale model, with a porosity of $2 \%$ can get a better result when using the model established in this paper to study the mechanical behavior of rubberized self-compacting concrete. Porosity-strength relations are proposed by fitting the results of parametric studies with different porosity and rubber content.

(5) Concrete containing rubber with fine grading has lower strength and toughness than concrete containing coarse rubber. Rubber content-strength relations for both fine grading and coarse grading rubber are proposed by fitting the results of parametric studies with different rubber contents.

The conclusions of this work form a useful guide for designing rubber concrete and a solid base for further experimental and modelling efforts.

\section{Data Availability}

The data used to support the findings of this study are available from the corresponding author upon request.

\section{Additional Points}

(1) 3D mesoscale modelling for damage and fracture analysis

(2) Investigation of critical mesostructural parameters performed

(3) Effects of porosity, rubber content, and particle size on strength established

(4) Fracture patterns related to postpeak softening response 


\section{Conflicts of Interest}

The authors declare that there are no conflicts of interest.

\section{Acknowledgments}

The research was based upon the work supported by the National Natural Science Foundation of China (52009122), Zhejiang Provincial Natural Science Foundation (LQ21E090002 and LGF20E080007), Science and Technology Project of Zhejiang Provincial Department of Transport in 2019 (2019007), and Zhejiang Provincial Department of Education general scientific research projects (Y201941345).

\section{References}

[1] K. M. Brown, R. Cummings, J. R. Mrozek, and P. Terrebonne, "Scrap tire disposal: three principles for policy choice," Natural Resources Journal, vol. 21, no. 1, 2001.

[2] I. B. Topcu, "The properties of rubberized concretes," Cement and Concrete Research, vol. 25, no. 2, pp. 304-310, 1995.

[3] N. N. Eldin and A. B. Senouci, "Rubber-tire particles as concrete aggregate," Journal of Materials in Civil Engineering, vol. 5, no. 4, pp. 478-496, 1993.

[4] H. Su, J. Yang, T.-C. Ling, G. S. Ghataora, and S. Dirar, "Properties of concrete prepared with waste tyre rubber particles of uniform and varying sizes," Journal of Cleaner Production, vol. 91, pp. 288-296, 2015.

[5] N. I. Fattuhi and L. A. Clark, "Cement-based materials containing shredded scrap truck tyre rubber," Construction and Building Materials, vol. 10, no. 4, pp. 229-236, 1996.

[6] N. A. Ali, A. D. Amos, and M. Roberts, "Use of ground rubber tires in Portland cement concrete," in Proceedings of The International Conference On Concrete, vol. 390, Thomas Telford Services Ltd, London, UK, 2000.

[7] H. A. Toutanji, "The use of rubber tire particles in concrete to replace mineral aggregates," Cement and Concrete Composites, vol. 18, no. 2, pp. 135-139, 1996.

[8] M. M. Reda Taha, A. S. El-Dieb, M. A. Abd El-Wahab, and M. E. Abdel-Hameed, "Mechanical, fracture, and microstructural investigations of rubber concrete," Journal of Materials in Civil Engineering, vol. 20, no. 10, pp. 640-649, 2008.

[9] B. Huang, G. Li, S.-S. Pang, and J. Eggers, "Investigation into waste tire rubber-filled concrete," Journal of Materials in Civil Engineering, vol. 16, no. 3, pp. 187-194, 2004.

[10] F. Liu, G. Zhong, X. Xia, and L. Li, "Mechanical analysis of rubberized concrete subjected to uniaxial compression on meso-level," Journal of Building Materials, vol. 13, pp. 733$738,2010$.

[11] Z. H. Xie, Y. C. Guo, Q. Z. Yuan, and P. Y. Huang, "Mesoscopic numerical computation of compressive strength and damage mechanism of rubber concrete," Advances in Materials Science and Engineering, vol. 2015, Article ID 279584, 10 pages, 2015.

[12] X. Li, X. Chen, A. P. Jivkov, and J. Zhang, "3D mesoscale modeling and fracture property study of rubberized selfcompacting concrete based on uniaxial tension test," Theoretical and Applied Fracture Mechanics, vol. 104, Article ID 102363, 2019.

[13] X. Q. Zhou and H. Hao, "Modelling of compressive behaviour of concrete-like materials at high strain rate," International
Journal of Solids and Structures, vol. 45, no. 17, pp. 4648-4661, 2008.

[14] H. Du, F. Dai, Y. Xu, Z. Yan, and M. Wei, "Mechanical responses and failure mechanism of hydrostatically pressurized rocks under combined compression-shear impacting," International Journal of Mechanical Sciences, vol. 165, Article ID 105219, 2019.

[15] J. Liu, D. Chen, Y. Wu, R. Chen, P. Yang, and H. Zhang, "Image edge recognition of virtual reality scene based on multi-operator dynamic weight detection," IEEE Access, vol. 8, pp. 111289-111302, 2020.

[16] S. Yang, B. Leshchinsky, K. Cui, F. Zhang, and Y. Gao, "Unified approach toward evaluating bearing capacity of shallow foundations near slopes," Journal of Geotechnical and Geoenvironmental Engineering, vol. 145, Article ID 04019110, 2019.

[17] J. Lee and G. L. Fenves, "Plastic-damage model for cyclic loading of concrete structures," Journal of Engineering Mechanics, vol. 124, no. 8, pp. 892-900, 1998.

[18] D. Systemes, Abaqus V6. 12 Documentation-ABAQUS Analysis User's Manual, Abaqus, Providence, RI, USA, 2012.

[19] G. Z. Z. X. Z. Dacheng and W. Ruqi, "Experimental investigation of the complete stress-strain curve of concrete," Journal of Building Structures, vol. 1, pp. 1-12, 1982.

[20] V. Birtel and P. Mark, "Parameterised finite element modelling of rc beam shear failure," in Proceedings of the ABAQUS Users' Conference, pp. 95-108, Providence, RI, USA, May 2006.

[21] P. Grassl and M. Jirasek, "Damage-plastic model for concrete failure," International Journal of Solids and Structures, vol. 43, no. 22-23, pp. 7166-7196, 2006.

[22] M. Emiroglu, M. H. Kelestemur, and S. Yildiz, "An investigation on ITZ microstructure of the concrete containing waste vehicle tire," in Proceedings of the 8th International Fracture Conference, pp. 7-8, 2007.

[23] Y. Xu and F. Dai, "Dynamic response and failure mechanism of brittle rocks under combined compression-shear loading experiments," Rock Mechanics and Rock Engineering, vol. 51, no. 3, pp. 747-764, 2018.

[24] S. Yang, B. Leshchinsky, K. Cui, F. Zhang, and Y. Gao, "Influence of failure mechanism on seismic bearing capacity factors for shallow foundations near slopes," Geotechnique, pp. 1-14, 2020.

[25] Y. Huang, Z. Yang, W. Ren, G. Liu, and C. Zhang, “3D mesoscale fracture modelling and validation of concrete based on in-situ X-ray Computed Tomography images using damage plasticity model," International Journal of Solids and Structures, vol. 67-68, pp. 340-352, 2015.

[26] H. Chen, B. Xu, Y. L. Mo, and T. Zhou, "Behavior of mesoscale heterogeneous concrete under uniaxial tensile and compressive loadings," Construction and Building Materials, vol. 178, pp. 418-431, 2018.

[27] P. Grassl, D. Gregoire, L. Rojas Solano, and G. PijaudierCabot, "Meso-scale modelling of the size effect on the fracture process zone of concrete," International Journal of Solids and Structures, vol. 49, no. 13, pp. 1818-1827, 2012.

[28] J. G. M. Van Mier and M. R. A. Van Vliet, "Influence of microstructure of concrete on size/scale effects in tensile fracture," Engineering Fracture Mechanics, vol. 70, no. 16, pp. 2281-2306, 2003.

[29] X. Wang, M. Zhang, and A. P. Jivkov, "Computational technology for analysis of 3D meso-structure effects on damage and failure of concrete," International Journal of Solids and Structures, vol. 80, pp. 310-333, 2016. 
[30] E. Roubin, A. Vallade, N. Benkemoun, and J.-B. Colliat, "Multi-scale failure of heterogeneous materials: a double kinematics enhancement for Embedded Finite Element Method," International Journal of Solids and Structures, vol. 52, pp. 180-196, 2015.

[31] X. F. Wang, Z. J. Yang, J. R. Yates, A. P. Jivkov, and C. Zhang, "Monte Carlo simulations of mesoscale fracture modelling of concrete with random aggregates and pores," Construction and Building Materials, vol. 75, pp. 35-45, 2015.

[32] X. Wang, Z. Yang, and A. P. Jivkov, "Monte Carlo simulations of mesoscale fracture of concrete with random aggregates and pores: a size effect study," Construction and Building Materials, vol. 80, pp. 262-272, 2015.

[33] T. C. Powers, "Structure and physical properties of hardened Portland cement paste," Journal of the American Ceramic Society, vol. 41, no. 1, pp. 1-6, 1958.

[34] T. Rabczuk and T. Belytschko, "Cracking particles: a simplified meshfree method for arbitrary evolving cracks," International Journal for Numerical Methods in Engineering, vol. 61, no. 13, pp. 2316-2343, 2004.

[35] T. Rabczuk and T. Belytschko, "A three-dimensional large deformation meshfree method for arbitrary evolving cracks," Computer Methods in Applied Mechanics and Engineering, vol. 196, no. 29-30, pp. 2777-2799, 2007.

[36] T. Rabczuk, G. Zi, S. Bordas, and H. Nguyen-Xuan, "A geometrically non-linear three-dimensional cohesive crack method for reinforced concrete structures," Engineering Fracture Mechanics, vol. 75, no. 16, pp. 4740-4758, 2008.

[37] A. Raza, A. Ahmad, and Q. U. Zaman Khan, "Numerical investigation of load-carrying capacity of GFRP-reinforced rectangular concrete members using $\mathrm{CDP}$ model in ABAQUS," Advances in Civil Engineering, vol. 2019, Article ID 1745341, 2019. 